(C) 2022, The Authors. Published by Elsevier Inc. and Fass Inc. on behalf of the American Dairy Science Association ${ }^{\circledR}$. This is an open access article under the CC BY license (http://creativecommons.org/licenses/by/4.0/).

\title{
Physiological adaptations in early-lactation cows result in differential responses to calcium perturbation relative to nonlactating, nonpregnant cows
}

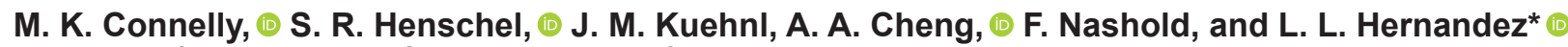 \\ Department of Animal and Dairy Sciences, University of Wisconsin, Madison 53706
}

\begin{abstract}
The peripartal cow experiences a rapid change in calcium metabolism at the onset of lactation. Research has focused on understanding how mammary-derived factors, such as serotonin (5HT) and parathyroid hormone like hormone (PTHLH), aid in coordinating these calcemic adaptations to lactation. Therefore, the aim of our study was to determine how induced subclinical hypocalcemia influences physiological responses, specifically the 5HT-PTHLH-Ca axis, in lactating and nonlactating dairy cows to elucidate the potential contribution of the mammary gland. Twelve nonlactating, nonpregnant (NL) multiparous Holstein cows and 12 early-lactation (EL) multiparous Holstein cows received either (1) a continuous 24-h intravenous solution of $0.9 \% \mathrm{NaCl}$ or (2) $5 \%$ ethylene glycol tetraacetic acid (EGTA) solution in $0.9 \% \mathrm{NaCl}(\mathrm{n}=6 \mathrm{EL}, \mathrm{n}=6 \mathrm{NL}$ per treatment) with the aim of maintaining blood ionized calcium (iCa) less than $1.0 \mathrm{~m} M$. Mammary gland biopsies were taken immediately after and $48 \mathrm{~h}$ after termination of infusion. Blood was sampled hourly during infusion and 4, 8, 12, 24, 48, and $72 \mathrm{~h}$ after termination of infusion. Infusion of EGTA successfully decreased blood iCa concentrations. However, EL EGTA-infused cows required increased rates of EGTA infusion to maintain iCa below $1.0 \mathrm{mM}$. Circulating and mammary serotonin concentrations were increased in EL relative to NL cows, with no difference as a result of EGTA infusion. Mammary PTHLH expression was increased in EL cows, with highest expression observed in EL EGTA-infused cows. Collectively, these data demonstrate the robust adaptations EL cows have to maintain Ca homeostasis and the supporting roles $5 \mathrm{HT}$ and PTHLH may play.
\end{abstract}

Key words: hypocalcemia, EGTA, PTHLH, serotonin

Received June 18, 2021.

Accepted August 26, 2021.

*Corresponding author: llhernandez@wisc.edu

\section{INTRODUCTION}

Calcium is a major mineral found in milk and critical for normal physiological function. The onset of lactation results in a rapid and robust increase in demand for $\mathrm{Ca}$ by the mammary gland, with dysregulation of blood Ca often occurring as blood and extracellular pools are drawn from at rates that cannot be maintained (Goff et al., 2002). Thus, poor regulation and maintenance of circulating $\mathrm{Ca}$ is a primary concern in dairy cows during the peripartal period as subclinical hypocalcemia (SCH) occurs in upwards of $50 \%$ of multiparous dairy cows (Reinhardt et al., 2011). The deleterious effects of SCH are numerous, with effects on cow health ranging from increased risk of displaced abomasum, metritis, mastitis, ketosis, and influence on neutrophil oxidative burst and function (Martinez et al., 2014; Merriman et al., 2019; McArt and Neves, 2020; Venjakob et al., 2021). The sole driver of peripartal Ca dysregulation has been demonstrated to come from the mammary gland, which acts as a sink for Ca at the onset of lactation (Goff et al., 2002). Thus, to adapt to the mammary glands' rapid and robust increase in demand and ensure maintenance of blood $\mathrm{Ca}$, a variety of endocrine and metabolic adaptations occur (Bauman and Bruce Currie, 1980).

Calcium homeostasis is classically regulated in a feedback loop controlled by 3 main hormones: parathyroid hormone (PTH), calcitonin, and 1,25-dihydroxyvitamin D. These hormones act in concert to support an integrated $\mathrm{Ca}$ metabolism in the peripartal cow by modulating intestinal $\mathrm{Ca}$ absorption, reabsorption of $\mathrm{Ca}$ at the kidney, and bone resorption to collectively maintain Ca homeostasis (Goff, 2000). As a result of the dairy cow's copious milk production and early-lactation negative $\mathrm{Ca}$ balance, intestinal and kidney pools are often not sufficient. Thus, the skeletal reservoir is extensively relied upon during lactation, with the dairy cow losing up to $13 \%$ of skeletal Ca during the first 6 to 8 wk postpartum (Horst et al., 2005; Kovacs, 2016). The immensity of Ca demand at the onset of lactation by the mammary gland often outcompetes $\mathrm{Ca}$ pool maintenance, resulting in an inability to maintain 
blood Ca concentrations despite increases in PTH and 1,25-dihydroxyvitamin D (Reinhardt et al., 2011; Rodney et al., 2018).

Subsequently, mammary-derived endocrine signals are often enacted to support the excessive adaptations in Ca homeostasis necessary for lactation (Kovacs, 2016). Two such mammary-derived endocrine signals, serotonin and parathyroid hormone like hormone (PTHLH), more commonly known as parathryoid hormone-related protein, have been shown to be regulators of $\mathrm{Ca}$ homeostasis during lactation (VanHouten et al., 2003; Laporta et al., 2013a). Serotonin is primarily produced by enterochromaffin cells in the gastrointestinal tract in a nonlactating state (Berger et al., 2009). However, during lactation, serotonin is substantially increased (Bornstein et al., 2014), with recent research demonstrating that mammary-derived serotonin contributes up to $50 \%$ of circulating serotonin concentrations in rodents during lactation (Weaver et al., 2017). During lactation, a unique relationship between serotonin and $\mathrm{Ca}$ exists, with increased circulating serotonin concentrations improving Ca homeostasis (Hernández-Castellano et al., 2017a; Slater et al., 2018) and increasing mammary PTHLH synthesis and secretion (Laporta et al., 2013a). During lactation, the mammary gland is the primary site of PTHLH synthesis (VanHouten et al., 2003) and has been referred to as an accessory parathyroid gland as a result of PTHLH's rigorous bone mobilization and Ca regulation (VanHouten et al., 2003; Weaver and Hernandez, 2018). Mammary-derived PTHLH has been postulated to play a more potent role in calcium homeostasis during lactation than PTH (Kovacs, 2016).

Research during the past 2 decades has focused on understanding serotonin and Ca metabolism and their relationship with one another. Supplementing the diet with the serotonin precursor 5-hydroxy-L-trytophan (5-HTP) to rodents during the peripartal period increased Ca mobilization and mammary PTHLH production (Laporta et al., 2013a). Further, when 5-HTP was infused prepartum in the dairy cow, an improvement in Ca homeostasis occurred postpartum (Weaver et al., 2016; Hernández-Castellano et al., 2017a; Slater et al., 2018). Interestingly, cows infused with 5-HTP had higher blood $\mathrm{Ca}$ concentrations despite absence of the classical PTH peak associated with parturition (Hernández-Castellano et al., 2017b). Correspondingly, serotonin has been shown to be positively correlated with blood $\mathrm{Ca}$ and PTHLH on $\mathrm{d} 1$ of lactation in dairy cows (Laporta et al., 2013b). Serotonin action is thought to drive $\mathrm{Ca}$ metabolism through eliciting transient hypocalcemia (Laporta et al., 2015; Connelly et al., 2021b), triggering negative feedback mechanisms and stimulating PTHLH synthesis, collectively allowing for improved Ca status and an improved adaptation to lactation. Although serotonin's regulation of Ca has been clearly demonstrated, the response of serotonin and PTHLH to systemic hypocalcemia remains poorly understood.

Therefore, the aim of our study was to determine the effects of induced $\mathrm{SCH}$ on the serotonin-PTHLH-Ca axis in early-lactation (EL) and nonlactating, nonpregnant (NL) dairy cows. We sought to elucidate how systemic SCH alters physiological responses in EL and NL cows and determine the contribution of the mammary gland during induced SCH using $5 \%$ ethylene glycol tetraacetic acid (EGTA). We hypothesized that SCH induction would alter serotonin concentrations in EL EGTA cows, with dynamic changes in mammary gland-derived processes such as PTHLH expression and mammary Ca metabolism genes in EL EGTA cows. Further, we hypothesized that SCH would modulate bone resorption markers in EL EGTA cows as a result of alterations in serotonin and PTHLH expression.

\section{MATERIALS AND METHODS}

\section{Animals and Experimental Design}

All experimental procedures performed in this study were approved by the College of Agriculture and Life Sciences Animal Care and Use Committee at the University of Wisconsin-Madison (care and use protocol guidelines A005316-R01). All cows were housed in an enclosed tiestall barn at the Dairy Cattle Center at the University of Wisconsin-Madison. Cows arrived at the Dairy Cattle Center 2 mo before the start of the experiment to allow for acclimation to tiestall housing and for pregnant cows to calve at the facility. Lactating cows were milked twice daily. Early-lactation cows were fed the herd lactating cow diet, and NL cows were fed the herd dry cow diet (Table 1). Diets were fed as a TMR, sampled weekly, and sent off for wet chemistry analysis at a commercial laboratory (Dairyland Labs, Arcadia, Wisconsin). Feed was mixed fresh daily and offered once at approximately $0900 \mathrm{~h}$, with orts weighed the following day to calculate daily DMI for each cow.

A total of 24 multiparous (2.9 \pm 0.14 lactations) Holstein dairy cows, 12 EL $(11.3 \pm 0.97$ DIM, $38.02 \pm$ $2.16 \mathrm{~kg} / \mathrm{d}$ milk yield) and $12 \mathrm{NL}$ cows were blocked by parity and day of infusion. All animals were subjected to a physical examination before enrollment. Early-lactation cows were enrolled only if checked free of ketosis, mastitis, and hypocalcemia during daily periparturient health checks for 3 consecutive days before experimental enrollment, as performed by herd staff. Cows were randomly assigned to receive a continuous 24 -h intravenous solution of either (1) $0.9 \%$ sterile $\mathrm{NaCl}(\mathrm{n}=6 \mathrm{EL}$, 
$\mathrm{n}=6 \mathrm{NL}$ ) or (2) 5\% EGTA solution dissolved in $0.9 \%$ $\mathrm{NaCl}(\mathrm{n}=6 \mathrm{EL}, \mathrm{n}=6 \mathrm{NL})$, with the aim of maintaining blood ionized calcium (iCa) less than $1.0 \mathrm{mM}$ for the duration of the $24-\mathrm{h}$ period. This experimental arrangement resulted in 4 treatments: $0.9 \% \mathrm{NaCl}$-infused nonlactating, nonpregnant (NL Saline), EGTA-infused nonlactating, nonpregnant (NL EGTA), saline-infused early lactation (EL Saline), and EGTA-infused early lactation (EL EGTA). Intravenous solution of $5 \%$ EGTA was prepared aseptically with approximately $900 \mathrm{~mL}$ of $0.9 \% \mathrm{NaCl}$ (Hospira Inc.), $50 \mathrm{~g}$ of EGTA (E3889, Sigma-Aldrich), and approximately $25 \mathrm{~mL}$ of $10 \mathrm{M} \mathrm{NaOH}$. The solution was continuously mixed until EGTA went into solution. Upon complete dissolvement, $\mathrm{pH}$ of the solution was measured, and additional $5 \mathrm{M}$ $\mathrm{NaOH}$ was added until the $\mathrm{pH}$ was adjusted to 7.4. The fully dissolved solution was then sterile filtered using a $0.22-\mu \mathrm{m}$ filter and labeled and stored at $4^{\circ} \mathrm{C}$ until use.

Infusions were performed for $24 \mathrm{~h}$ beginning at approximately $0900 \mathrm{~h}$ on the day of infusion and concluding the following morning at $0900 \mathrm{~h}$. Normocalcemic cows were continuously intravenously infused with saline, whereas SCH cows were continuously infused with a 5\% EGTA solution. An infusion pump (Heska Vet IV) was used to maintain and control rate of infusion equally between paired normocalcemic and EGTAinfused cows. Infusion rates were determined based on blood iCa concentrations of the EGTA-infused cows, with hourly blood samples taken during the infusion period. Cows induced into SCH started infusion at 500 $\mathrm{mL} / \mathrm{h}$ until blood iCa fell below $1.0 \mathrm{~m} M$, at which time infusion rate was modified hourly in accordance with blood iCa concentrations measured by CG8+ cartridg-

Table 1. Nutrient composition in dry and lactating cow diets fed during the experimental period

\begin{tabular}{lcc}
\hline Item & Dry & Lactating \\
\hline Nutrient & \\
DM & \% of DM) & \\
$\mathrm{CP}$ & 47.5 & 49.9 \\
Starch & 12.1 & 17.1 \\
$\mathrm{ADF}$ & 21.4 & 24.8 \\
$\mathrm{NDF}$ & 29.2 & 23.1 \\
$\mathrm{NFC}$ & 43.9 & 30.9 \\
NE $(\mathrm{Mcal} / \mathrm{kg})$ & 37.3 & 40.9 \\
$\mathrm{Mineral}^{1}(\%$ of DM) & 1.45 & 1.60 \\
$\mathrm{Ca}$ & & \\
$\mathrm{P}$ & 0.55 & 0.78 \\
$\mathrm{Mg}$ & 0.35 & 0.41 \\
$\mathrm{~K}$ & 0.27 & 0.36 \\
$\mathrm{~S}$ & 1.19 & 1.60 \\
$\mathrm{Na}$ & 0.23 & 0.20 \\
$\mathrm{Cl}$ & 0.11 & 0.43 \\
$\mathrm{DCAD}^{2}(\mathrm{mEq} / \mathrm{kg})$ & 0.29 & 0.52 \\
\hline
\end{tabular}

\footnotetext{
${ }^{1}$ Wet chemistry analysis (Dairyland Laboratories).

${ }^{2} \mathrm{DCAD}$ calculations were based upon the following equation: DCAD $(\mathrm{mEq} / \mathrm{kg})=[(\mathrm{Na}+\mathrm{K})-(\mathrm{Cl}+\mathrm{S})]$.
}

es read using a cow-side handheld biochemical analyzer (i-Stat System, Abbott Laboratories). Saline cows were infused at the same rate as their pair-matched EGTA cow of the same physiological state within the same block, resulting in separate EGTA infusion rates for early-lactation and nonlactating, nonpregnant cows. The objective was to maintain iCa concentrations below $1.0 \mathrm{~m} M$ for the entirety of the 24 -h infusion period and ensure that the normocalcemic cows received equal volumes of fluid relative to their pair-matched EGTA cow. The selection of $1.0 \mathrm{mM}$ iCa for definition of $\mathrm{SCH}$ was based upon previous work (Martinez et al., 2014).

\section{Sample Collection}

Before initiation of the experimental period, a jugular catheter was inserted into each jugular vein. Catheter placement and maintenance was performed as previously described (Slater et al., 2018). During continuous infusion, one catheter was used for intravenous infusion and the opposing for blood sampling. Mammary gland biopsies were performed at 24 and $72 \mathrm{~h}$ relative to start of infusion and were conducted as previously described for the following: sedation, surgical preparation, surgical technique, and cow health monitoring (Slater et al., 2018; Connelly et al., 2021b). Mammary gland tissues were immediately rinsed in $1 \times$ PBS, sectioned for respective laboratory analysis, promptly snap-frozen in liquid nitrogen, and stored at $-80^{\circ} \mathrm{C}$ until analysis.

Baseline blood samples were all collected via the coccygeal vein before initiation of the experimental period. Before whole blood collection, $8 \mathrm{~mL}$ of blood were drawn and discarded to remove any residual heparinized saline, with whole blood subsequently collected from catheters. Blood was then sampled from the jugular catheter immediately before start of infusion, hourly during the infusion, and 4, 8, 12, 24, 48, and $72 \mathrm{~h}$ after termination of infusion. Whole blood was collected into a 10-mL BD Vacutainer K2 EDTA Plus (368589, Becton, Dickinson and Company), 10-mL BD Vacutainer Serum (367820, Becton, Dickinson and Company), and 10-mL Lithium Heparin 158 USP Units (367880, Becton, Dickinson and Company) blood collection tubes and inverted gently. Immediately following inversion, 3 to $4 \mathrm{~mL}$ of whole blood was transferred from the 10-mL BD Vacutainer K2 EDTA Plus tube into a 5-mL Eppendorf preloaded with approximately $35 \mathrm{mg}$ of ascorbic acid (10 mg/mL) to stabilize and protect against oxidative loss of serotonin, and frozen at $-20^{\circ} \mathrm{C}$ until analysis (Connelly et al., 2021b). Blood samples collected for serum analysis were maintained at room temperature and allowed to clot before being placed at $4^{\circ} \mathrm{C}$ until processing. Respective blood fractions were isolated from Vacutainer collection tubes by 
centrifugation at $3,000 \times g$ for $20 \mathrm{~min}$ at $4^{\circ} \mathrm{C}$. Samples were then divided into multiple aliquots and stored at $-80^{\circ} \mathrm{C}$ until analysis.

Urine samples were obtained immediately before the infusion, every $8 \mathrm{~h}$ during infusion and $12,24,48$, and $72 \mathrm{~h}$ after termination of infusion. Urine was collected by gently massaging the area between the udder and the vulva. Samples were collected midstream in $5-\mathrm{mL}$ Eppendorf tubes and stored at $-20^{\circ} \mathrm{C}$ until analysis. Milk samples were collected during the morning and evening milking starting $2 \mathrm{~d}$ before the beginning of the experimental period and continuing through the experimental period. Milk samples were collected in $5-\mathrm{mL}$ Eppendorf tubes and stored at $-20^{\circ} \mathrm{C}$ until analysis.

\section{Serum and Milk Laboratory Analyses}

Serotonin concentrations were analyzed in whole blood (IM1749, Immunotech, Beckman Coulter) according to manufacturer's instructions and as previously described (Laporta et al., 2015; Slater et al., 2018). The intra- and interassay coefficients of variation (CV) for blood serotonin were $2.47 \%$ and $10.49 \%$, respectively. Total serum calcium (tCa) and urine concentrations were determined using a colorimetric Ca assay (700550, Cayman Chemical) per manufacturer's instructions as previously described (Laporta et al., 2015), with serum Ca intra- and interassay CV 2.79\% and 3.99\%, respectively. Urine $\mathrm{Ca}$ intra- and interassay $\mathrm{CV}$ were $2.79 \%$ and $4.75 \%$, respectively. Urine Ca concentrations were corrected to creatinine to adjust for urine volume. Urine creatinine was determined by colorimetric assay (DICT-500, QuantiChrom Creatinine Assay Kit, BioAssay Systems) as described previously (Slater et al., 2018), with intra- and interassay CV $4.13 \%$ and $8.67 \%$, respectively. Serum pyridinoline (PYD) concentrations were analyzed using a MicroVue PYD EIA Kit (8019, Quidel MicroVue) with intra- and interassay $\mathrm{CV}$ of $3.21 \%$ and $5.58 \%$. Milk Ca concentration was determined by colorimetric assay (DICA-500, QuantiChrom Calcium Assay) and diluted 1:25 (Connelly et al., 2021b), with intra- and interassay CV $4.80 \%$ and $6.65 \%$, respectively. Deoxypyridinoline (DPD) was measured in urine and corrected to creatinine (DPD MicroVue Bone Health, ALPCO) as previously described (Slater et al., 2018), with intra- and interassay CV $3.62 \%$ and $9.77 \%$, respectively.

\section{Protein Isolation and Analysis}

Protein was isolated from mammary tissue via radioimmunoprecipitation assay buffer for serotonin content and Triton lysate buffer for Ca content, with $10 \mu \mathrm{L} / \mathrm{mL}$ of Halt Protease and Phosphatase Inhibitors Cocktail
(78441, Thermo Scientific) added. Protein concentrations were determined by Bicinchoninic Acid Assay (20831001-1, Bioworld) with intra- and interassay CV of $4.14 \%$ and $3.71 \%$. Mammary serotonin (Serotonin EIA Kit, IM1749, Immunotech, Beckman Coulter) and Ca content (700550, Cayman Chemical) were determined as previously described (Connelly et al., 2021b). Serotonin intra- and interassay CV were $5.50 \%$ and $5.53 \%$, respectively. Calcium intra- and interassay CV were $2.09 \%$ and $3.02 \%$, respectively.

\section{Mammary Gland Gene Expression}

Total RNA was isolated from mammary tissue using the miRNeasy Mini Kit (Qiagen) according to the manufacturer's instructions. Total RNA was quantified by Nanodrop spectrophotometer (ND-1000, Nanodrop Technologies). One microgram of RNA was reversetranscribed to cDNA using the Applied Biosystems High Capacity cDNA Reverse Transcription Kit (4368814, Applied Biosystems). Following reverse transcription, cDNA was diluted (1:5) in molecular-grade water, and quantitative real-time PCR was performed using a CFX96 Touch Real-Time PCR Detection System (Bio-Rad Laboratories). Primer design, cycling conditions, and reaction mixtures were performed as previously described (Slater et al., 2018). Mammary gland expression of genes involved in Ca metabolism were evaluated with genes and primer sequences supplied (Table 2). The geometric mean of keratin $8(K 8)$, ribosomal protein $9(R S P 9)$, and cyclophilin A (CypA) was used as the housekeeping parameter. Data were analyzed using the $2^{-\Delta \Delta \mathrm{Ct}}$ method, with NL Saline group at $24 \mathrm{~h}$ serving as the internal control (Livak and Schmittgen, 2001).

\section{Statistical Analysis}

Data were analyzed using the MIXED procedure of SAS (version 9.4, SAS Institute Inc.). Baseline measurements were determined using the average of 1 to $3 \mathrm{~d}$ before treatment and were then included as a covariate for the respective analysis. Fixed terms in the model for blood and urine variables were infusion, stage, hour, block, covariate, and the interactions of infusion $\times$ stage, infusion $\times$ hour, stage $\times$ hour, and infusion $\times$ stage $\times$ hour. Fixed terms in the model for gene expression and mammary content were infusion, stage, hour, block, and the interactions of infusion $x$ stage, infusion $x$ hour, stage $x$ hour, and infusion $x$ stage $\times$ hour. Due to saline-matched infusion rates, the model for evaluating infusion rate responses were for groups that were modified only (NL EGTA and EL EGTA) and included the fixed terms of stage, hour, 
Table 2. Primer sequences used for quantitative real-time PCR performed in multiparous Holstein dairy cows ${ }^{1}$

\begin{tabular}{lll}
\hline Gene & Forward primer $5^{\prime}-3^{\prime}$ & Reverse primer $3^{\prime}-5^{\prime}$ \\
\hline ORAI1 & GGCGCAAACTCTACTTGAGC & GGTAGTCGTGGTCAGCATCC \\
PMCA2 & CATCAAGTGTGGCATCATCC & TGGCCAGATCTTATCGATCC \\
PTHLH & GGAGGCTAGTTCAGCAATGG & CCGAGGTAGCTCTGATTTCG \\
CASR & ACACGTGGTCCAAGAGAGC & CAGCAGTATGCCATTCAACG \\
K8 & GATGAACCGGAACATCAACC & GCCTGACATCCTTAACAGC \\
RPS 9 & GGAGACCCTTCGAGAAGTCC & CTTTCTCATCCAGCGTCAGC \\
CypA & CACCGTGTTCTTCGACATCG & ACAGCTCAAAAGAGACGCGG \\
\hline
\end{tabular}

${ }^{1}$ All primers were designed and sequences obtained as in Slater et al. (2018). Reactions were run at an annealing temperature of $60^{\circ} \mathrm{C}$. The geometric mean of $K 8, R S P 9$, and $C y p A$ was used as the housekeeping parameter.

block, and the interaction of stage $\times$ hour, whereas the mean average infusion rate model contained the fixed terms of infusion, stage, block, and infusion $\times$ stage. Two separate analyses were used, to fit the proper covariance structure per sampling frequency. Hour was considered the repeated measure in both analyses. The first analysis included the first $24 \mathrm{~h}$ of infusion and, to account for autocorrelated errors, used the ar(1) structure. The second analysis was the sampling timeframe after termination of infusion and used the spatial power structure. Fixed terms within the model for milk yield and milk $\mathrm{Ca}$ included infusion, day, block, covariate, and the interaction of infusion $\times$ day. Fixed terms in the model for DMI were infusion, stage, hour, block, covariate, and the interactions of infusion $\times$ stage, infusion $\times$ hour, stage $\times$ hour, and infusion $\times$ stage $\times$ hour. Day or milking was considered the repeated measure for milk yield, milk Ca, and DMI, and autocorrelated errors were accounted for via the $\operatorname{ar}(1)$ structure. The random statements in all models included cow (stage $\times$ infusion). Data were analyzed for normality, and, when that assumption failed, data were transformed. Transformations were based on diagnostic plots and overall model fit, with either rank or log-transformation performed on response variables to improve normality. If transformation was required in one analysis, it was thus transformed in the adjoining analysis, to maintain consistency. Pairwise comparisons were performed using the adjustment of Tukey. Statistical significance was declared at $P \leq 0.05$, with tendencies for differences declared at $0.05 \leq P \leq 0.10$.

\section{RESULTS}

\section{Subclinical Hypocalcemic Induction}

Infusion of EGTA effectively decreased circulating iCa concentrations in both EL and NL cows $(P<0.0001)$ during the infusion period (Figure 1A). Interestingly, during maintenance of SCH, EL EGTA cows tended to have higher iCa concentrations during the duration of the infusion period relative to NL EGTA cows $(P$ $=0.08 ; 0.90 \pm 0.01$ vs. $0.84 \pm 0.01 \mathrm{~m} M$, respectively). An effect of stage was observed $(P=0.03)$, with EL cows exhibiting higher iCa concentrations relative to NL counterparts (Figure 1A). Similar changes in blood tCa were also observed (Figure 1B). Infusion of EGTA successfully decreased tCa concentrations $(P<0.0001)$ during the infusion period, with EL cows tending to have higher tCa concentrations relative to NL cows $(P=0.06)$ across the infusion period. No difference in infusion rates were observed as a result of infusion (saline or EGTA) due to pair-matched volume equivalencies (Figure 1C; $P>0.05$ ). Early-lactation EGTA cows required higher rates of EGTA infusion across the infusion period to maintain SCH compared with NL EGTA-infused cows $(P=0.003 ; 530.61 \pm 33.21$ vs. $310.76 \pm 33.21 \mathrm{~mL} / \mathrm{h}$, respectively), beginning $11 \mathrm{~h}$ into the infusion period and maintaining for the remainder of the infusion period (Figure 1D; $P \leq 0.05$ ).

\section{Post-Termination Ca Responses}

Blood iCa and tCa were influenced by both stage $(P$ $=0.05$ and $P=0.003$, respectively) and infusion $(P=$ 0.005 and $P=0.01$, respectively), with EL- and EGTAinfused cows having higher blood Ca concentrations. Four hours after termination of infusion $(28 \mathrm{~h})$, NL EGTA and EL EGTA groups had recovered blood Ca concentrations $(1.15 \pm 0.02$ and $1.28 \pm 0.02 \mathrm{mM}$ iCa; $2.13 \pm 0.09$ and $2.42 \pm 0.09 \mathrm{mM}$ tCa, respectively). At this same time point, iCa was increased in EL EGTA cows relative to NL EGTA $(P=0.004$; Figure 1A). An interaction of infusion by stage was observed $(P=$ 0.0001), with EL EGTA cows having the highest iCa concentrations relative to all other treatments in the time following termination of infusion $(P<0.009$; Figure 1A). The highest iCa concentrations were observed at $24 \mathrm{~h}$ after termination of infusion $(1.36 \pm 0.02 \mathrm{mM})$ in EL EGTA cows. Concentrations of tCa were also increased in EL EGTA cows relative to all other treatments in the period following termination of infusion $(P$ 

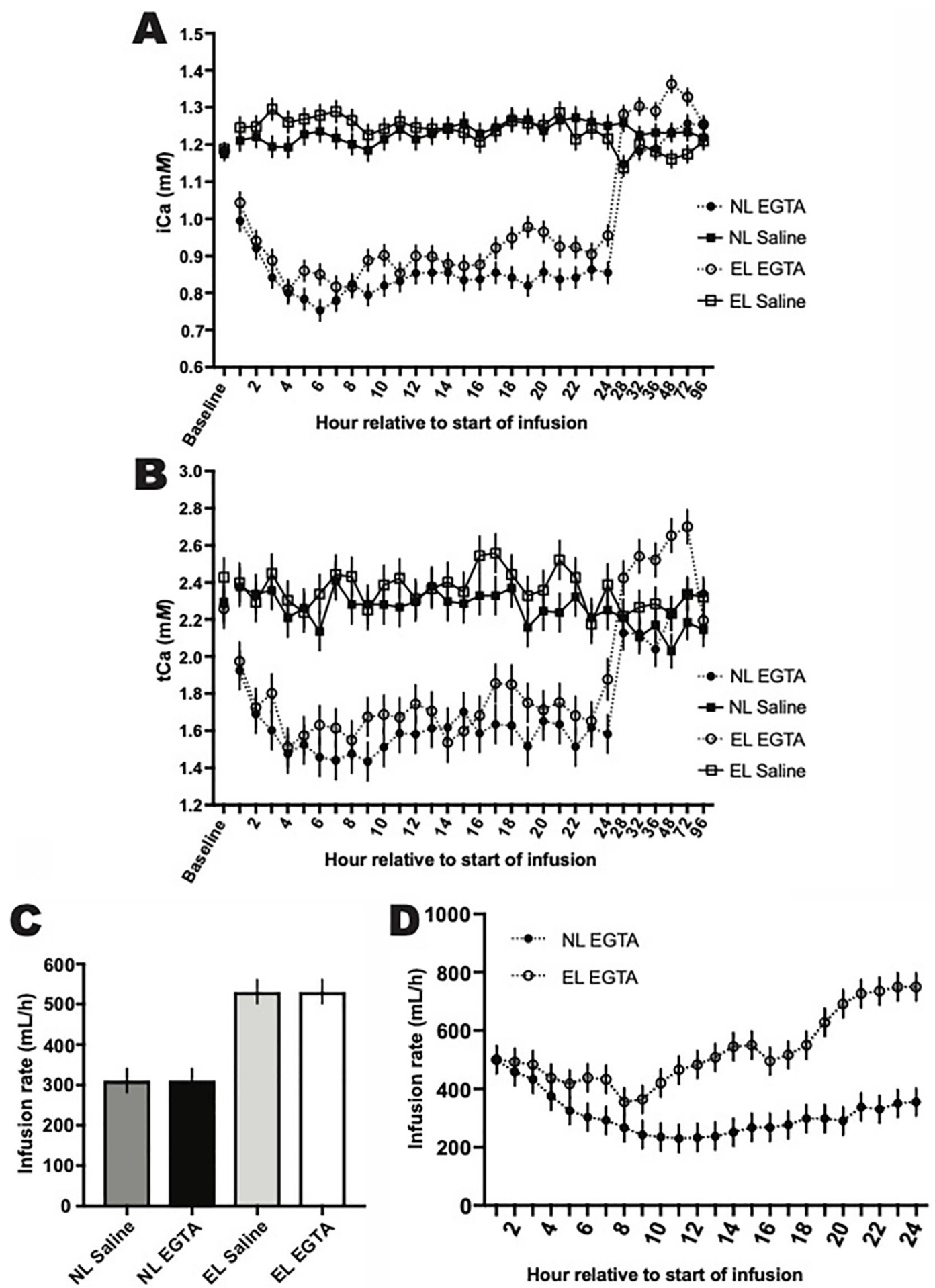

Hour relative to start of infusion

Figure 1. Whole blood ionized calcium (iCa) concentrations (A), serum total calcium (tCa) concentrations (B), and mean average infusion rates (C) and hourly infusion rates across the 24-h infusion period (D) of nonlactating, nonpregnant (NL) or early-lactation (EL) cows infused with 5\% ethylene glycol tetraacetic acid (NL EGTA and EL EGTA) or saline (NL Saline and EL Saline) for $24 \mathrm{~h}$. Ionized calcium concentrations: infusion $(24 \mathrm{~h}: P<0.0001$; post-termination: $P=0.005)$, stage $(24 \mathrm{~h}: P=0.03$; post-termination: $P=0.05)$, hour $(24$ h: $P=0.002)$, infusion $\times$ hour $(24 \mathrm{~h}: P=0.0004$; post-termination: $P=0.02$ ), stage $\times$ hour (post-termination: $P=0.01$ ), infusion $\times$ stage (post-termination: $P=0.0001)$, and infusion $\times$ stage $\times$ hour (post-termination: $P=0.002)$. Serum total calcium concentrations: infusion $(24$ h: $P<0.0001 ;$ posttermination: $P=0.01$ ), stage (post-termination: $P=0.003$ ), hour $(24 \mathrm{~h}: P<0.0001$ ), infusion $\times$ hour $(24$ h: $P=0.10)$, and infusion $\times$ stage $\times$ hour (post-termination: $P=0.01)$. Infusion rates mean average $(\mathrm{C})$ : stage $(P<0.0001)$. Infusion rates $(\mathrm{D})$ : stage $(P=0.003)$, hour $(P=$ $0.0002)$. Data presented as LSM \pm SEM. 
$<0.03$; Figure 1B). However, by $72 \mathrm{~h}$ after termination of infusion no difference was detectable between any groups in tCa or iCa concentrations $(P>0.05)$.

\section{Circulating and Mammary Serotonin Concentrations}

Infusion of EGTA did not alter circulating serotonin concentrations during the 24-h infusion period nor during the period after termination of infusion $(P>0.05$; Figure 2A-C). However, circulating serotonin concentrations were altered by stage. Early-lactation cows had higher $(P=0.03)$ circulating serotonin concentrations during the infusion period relative to NL cows (2,730 vs. $2,361 \mathrm{ng} / \mathrm{mL}$, respectively). The elevation in circulating serotonin concentrations in EL cows was observed in both analyses, with EL cows also having a tendency for elevated circulating serotonin concentration $(P=$ 0.09) after termination of infusion. Additionally, mammary serotonin content was influenced by stage, with EL cows having elevated mammary serotonin content relative to NL cows $(P=0.02$; Figure $2 \mathrm{D})$. Interestingly, no differences in mammary serotonin content were observed because of EGTA infusion $(P>0.05)$.

\section{$D P D$ and PYD Concentrations}

Urine DPD concentrations were increased in EL relative to NL cows during the infusion period $(P=$ $0.004 ; 7.06$ vs. $4.48 \mathrm{~m} M$, respectively) and following termination of infusion $(P=0.003 ; 6.33$ vs. $3.83 \mathrm{~m} M$; Figure 3A). However, no differences were observed as a result of EGTA infusion during the infusion period $(P>0.05)$. Interestingly, after termination of infusion, EGTA-infused cows had lower DPD concentrations relative to saline-infused cows $(P=0.05)$. Serum PYD was unchanged in response to EGTA infusion $(P>$ $0.05)$ but was numerically elevated in EL EGTA cows. An effect of stage was evident, with PYD being elevated in EL relative to NL cows $(P=0.04 ; 5.4$ vs 4.4 $\mathrm{n} M$, respectively; Figure 3B).

\section{Acid-Base Balance}

Infusion of EGTA decreased blood $\mathrm{pH}(P=0.0001)$ during the 24-h infusion period and after termination of infusion $(P=0.002)$ relative to saline-infused cows. Early-lactation cows had increased blood $\mathrm{pH}$ during the infusion period $(P=0.04)$ and after termination of infusion $(P=0.02)$ relative to NL counterparts (Table 3). Early-lactation cows tended to have increased $\mathrm{HCO}_{3}{ }^{-}$during the infusion period $(P=0.06)$, but no differences were detected in the period following termination of infusion $(P>0.05$; Table 3$)$. Cows infused with EGTA had decreased $\mathrm{HCO}_{3}{ }^{-}$during the 24-h infusion but elevated $\mathrm{HCO}_{3}^{-}$after termination of infusion relative to saline-infused cows $(P=0.004$ and $P=0.001$, respectively; Table 3$)$. Base excess was depressed in response to EGTA infusion $(P=0.001)$, with an effect of stage evident $(P=0.05)$, as NL cows had decreased base excess during the 24-h infusion. For the period after termination of infusion, cows infused with EGTA had higher base excess $(P=0.001)$ relative to saline-infused cows. Further, EL cows tended to have higher base excess $(P=0.08)$ relative to NL cows (Table 3). Nonlactating, nonpregnant cows had lower partial pressure of $\mathrm{CO}_{2}$ relative to EL cows during the infusion period $(P=0.02)$; however, no differences were observed as a result of stage after termination $(P>$ 0.05). Infusion of EGTA did not alter partial pressure of $\mathrm{CO}_{2}$ during the continuous $24 \mathrm{~h}$ or during the period following termination of infusion. No differences were observed in $\mathrm{Na}$ concentrations between stages $(P>$ 0.05), but EGTA infusion increased Na during the 24-h infusion $(P=0.03)$. No changes were observed with stage or infusion after termination of infusion $(P>$ 0.05; Table 3). Concentrations of $\mathrm{K}$ were not altered in response to infusion across the experimental period $(P>0.05)$. However, EL cows had higher K concentrations $(P=0.002)$ during the infusion period relative to NL counterparts (Table 3 ).

\section{Milk, Urine, and Tissue Ca Concentrations}

No differences in milk Ca concentrations were observed in EL EGTA cows compared with EL Saline $(P>0.05 ;$ Figure 4A). Stage of lactation did not alter urine $\mathrm{Ca}$ concentrations during the infusion period. However, decreased urine Ca concentrations $(P=0.03)$ were observed as a result of EGTA infusion. Following termination of infusion, an effect of stage $(P=0.03)$ and infusion $(P<0.0001)$ were present, as EL- and EGTA-infused cows had increased urine Ca excretion (Figure 4B). Infusion of EGTA did not alter mammary tissue Ca content $(P>0.05)$. However, EL cows had substantially increased mammary Ca content relative to NL cows $(P=0.01 ; 4.39 \pm 0.31$ vs. $3.21 \pm 0.31 \mathrm{mM} /$ mg of protein, respectively; Figure $4 \mathrm{C})$.

\section{Mammary Gland Gene Expression}

Expression of mammary PTHLH was influenced by both infusion $(P=0.0003)$ and stage $(P<0.0001)$, with EL- and EGTA-infused cows having substantially increased mammary PTHLH expression (Figure 5A). An interaction between infusion and stage occurred $(P$ $=0.002$ ), with a 100- to 200-fold increase in PTHLH expression observed in EL EGTA-infused cows pending time point. Early-lactation EGTA cows had robustly 

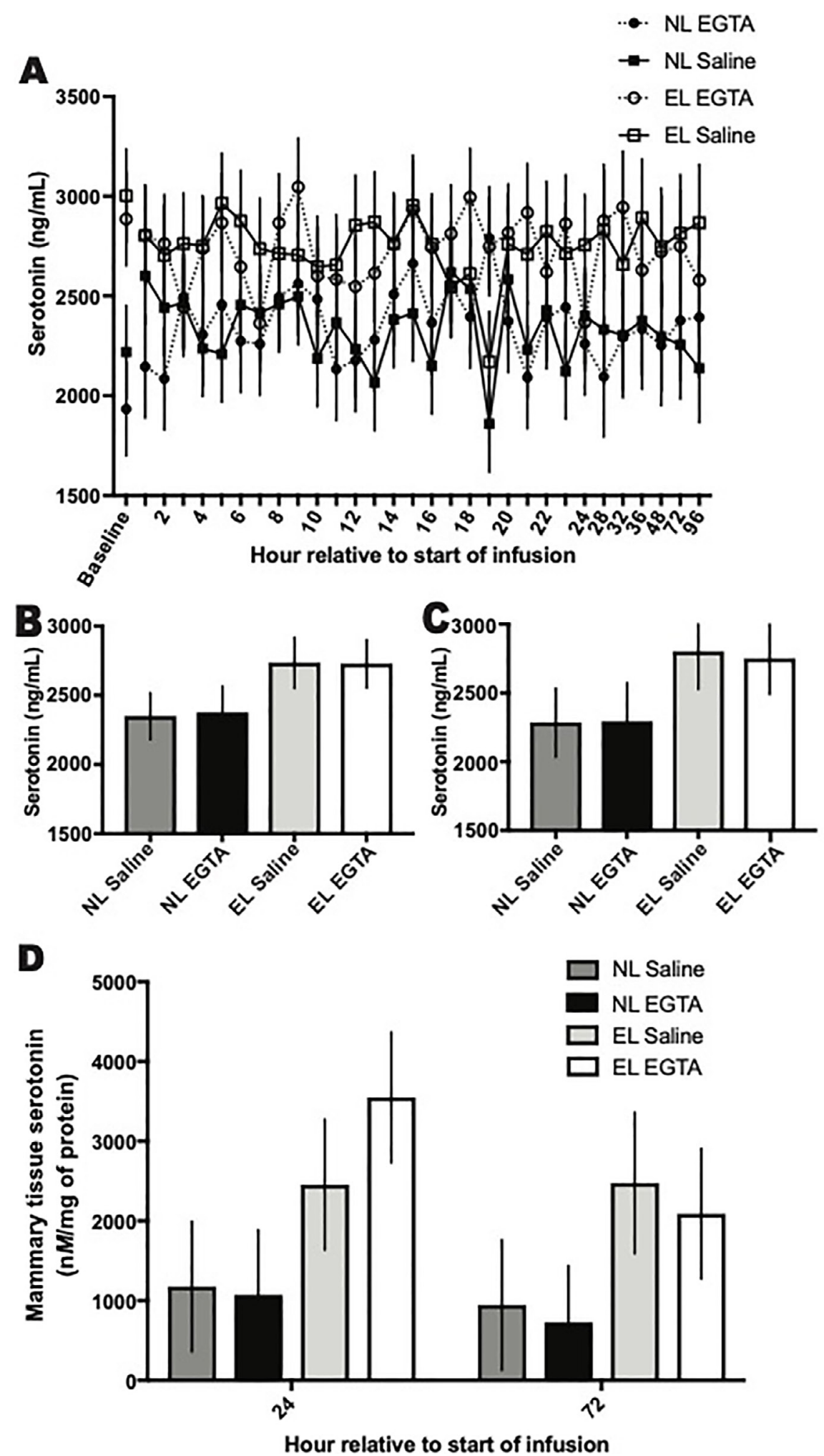

Figure 2. Concentrations of whole blood serotonin across the experimental period (A), mean average of whole blood serotonin during the infusion period (B), mean average of whole blood serotonin following termination of infusion (C), and mammary gland serotonin content (D) in nonlactating, nonpregnant (NL) or early-lactation (EL) cows infused with 5\% ethylene glycol tetraacetic acid (NL EGTA and EL EGTA) or saline (NL Saline and EL Saline) for $24 \mathrm{~h}$. Whole blood serotonin concentrations: stage $(24 \mathrm{~h}: P=0.03$; post-termination: $P=0.09)$, hour $(24$ h: $P=0.03)$, infusion $\times$ hour $(24$ h: $P=0.03$ ), and infusion $\times$ hour $\times$ stage (post-termination: $P=0.06)$. Mammary serotonin concentrations: stage $(P=0.02)$. Data presented as LSM \pm SEM. 
Table 3. Effect of induced subclinical hypocalcemia on acid-base status and blood parameters in multiparous nonlactating, nonpregnant and early-lactation Holstein cows during the experimental period (results expressed as LSM)

\begin{tabular}{|c|c|c|c|c|c|c|c|c|}
\hline Item $^{1}$ & \multicolumn{2}{|c|}{ Nonlactating, nonpregnant } & \multicolumn{2}{|c|}{ Early lactation } & SEM & \multicolumn{3}{|c|}{$P$-value } \\
\hline $\mathrm{pH}$ & 7.39 & 7.42 & 7.41 & 7.44 & 0.006 & 0.0001 & 0.04 & 0.96 \\
\hline $\mathrm{HCO}_{3}(\mathrm{~m} M)$ & 22.89 & 25.40 & 24.42 & 26.51 & 0.64 & 0.004 & 0.06 & 0.74 \\
\hline $\mathrm{BE}(\mathrm{m} M)$ & -2.22 & 1.05 & -0.33 & 2.45 & 0.73 & 0.001 & 0.05 & 0.75 \\
\hline $\mathrm{pCO}_{2}(\mathrm{~mm} \mathrm{Hg})$ & 36.78 & 38.72 & 39.60 & 39.78 & 0.73 & 0.22 & 0.03 & 0.25 \\
\hline \multicolumn{9}{|l|}{ Post-termination } \\
\hline $\mathrm{pH}$ & 7.46 & 7.43 & 7.47 & 7.45 & 0.006 & 0.002 & 0.02 & 0.73 \\
\hline $\mathrm{HCO}_{3}(\mathrm{~m} M)$ & 30.74 & 27.12 & 30.66 & 29.12 & 0.62 & 0.001 & 0.15 & 0.11 \\
\hline $\mathrm{BE}(\mathrm{m} M)$ & 6.94 & 2.85 & 7.18 & 5.25 & 0.67 & 0.001 & 0.08 & 0.13 \\
\hline $\mathrm{pCO}_{2}(\mathrm{~mm} \mathrm{Hg})$ & 42.76 & 40.46 & 41.85 & 41.62 & 0.83 & 0.19 & 0.88 & 0.23 \\
\hline $\mathrm{Na}(\mathrm{m} M)$ & 141.14 & 141.26 & 140.15 & 140.12 & 0.60 & 0.32 & 0.08 & 0.81 \\
\hline $\mathrm{K}(\mathrm{m} M)$ & 3.82 & 3.88 & 3.86 & 3.93 & 0.08 & 0.48 & 0.64 & 0.98 \\
\hline
\end{tabular}

${ }^{1} \mathrm{HCO}_{3}=$ bicarbonate; $\mathrm{BE}=$ base excess; $\mathrm{pCO}_{2}=$ partial pressure of $\mathrm{CO}_{2}$.

elevated mammary $P T H L H$ expression relative to all other treatments across the experimental period $(P \leq$ 0.0002). Interestingly, relative expression of calciumsensing receptor $(C A S R)$ demonstrated reciprocal expression of $P T H L H$ expression. Infusion did not alter $(P>0.05)$ mammary $C A S R$ expression, but $C A S R$ was significantly altered in response to stage. Across the experimental period, EL cows had 1- to 2-fold lower expression of $C A S R$ relative to NL cows $(P<0.0001$; Figure 5B). Mammary expression of PMCA2 tended to be increased in response to EGTA infusion $(P=0.10)$ and in EL cows $(P=0.10$; Figure $5 \mathrm{C})$. Moreover, an infusion $\times$ time interaction was observed $(P<0.0001)$, with an increase in PMCA2 expression at $72 \mathrm{~h}$ in EGTA cows relative to saline-infused stage counterparts (NL EGTA vs. NL Saline, $P=0.09$; EL EGTA vs. EL Sa- line, $P=0.06)$. No effect of infusion was observed $(P$ $>0.05)$ on ORAI1 expression in the mammary gland (Figure 5D). However, EL cows had increased mammary ORAI1 expression relative to NL cows $(P=$ 0.005), with EL EGTA cows having increased ORAI1 expression relative to NL Saline and NL EGTA cows $(P<0.05)$.

\section{Blood Glucose, Milk Yield, and DMI}

No differences were observed in glucose concentrations as a result of infusion during the 24-h infusion period or following termination of infusion $(P>0.05$; Figure $6 \mathrm{~A})$. However, an effect of stage was observed during the infusion period $(P=0.008)$ and after termination of infusion $(P=0.0006)$. Nonlactating, nonpregnant cows
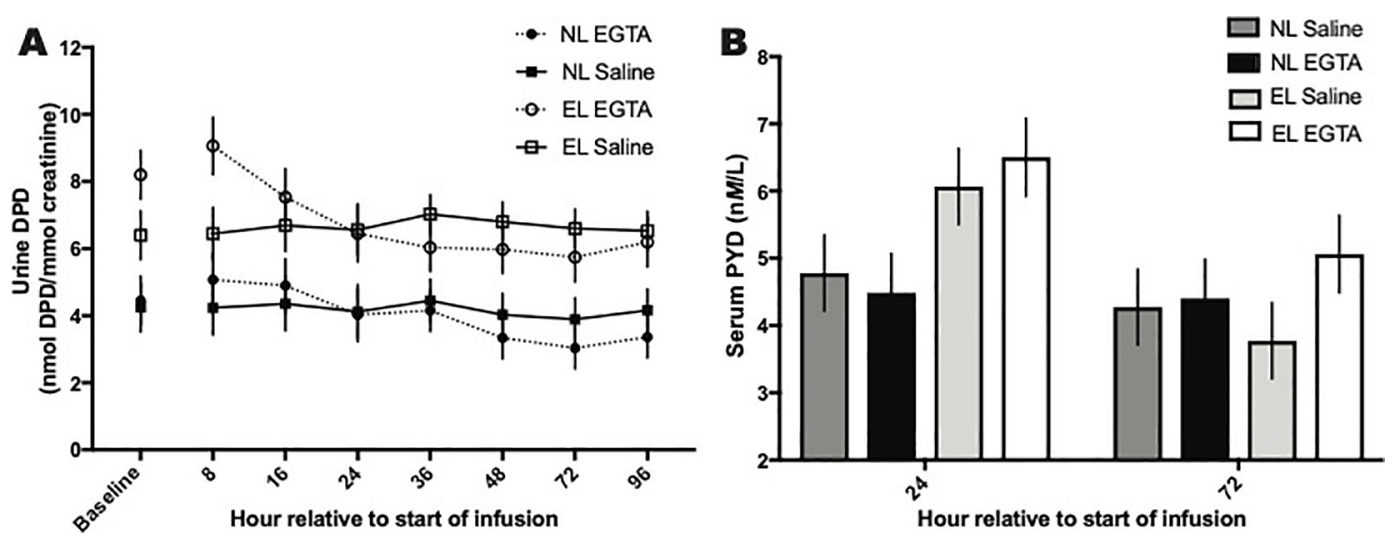

Figure 3. Concentrations of urine deoxypyridinoline (DPD; A) and serum pyridinoline (PYD; B) in nonlactating, nonpregnant (NL) or early-lactation (EL) cows infused with 5\% ethylene glycol tetraacetic acid (NL EGTA and EL EGTA) or saline (NL Saline and EL Saline) for 24 h. Urine DPD concentrations: infusion (post-termination: $P=0.05)$, stage $(24 \mathrm{~h}: P=0.004$; post-termination: $P=0.003)$, and hour (posttermination: $P=0.05)$. Serum PYD concentrations: stage $(P=0.04)$, time $(P<0.0001)$, and infusion $\times$ time $(P=0.02)$. Data presented as $\mathrm{LSM} \pm \mathrm{SEM}$. 
had elevated circulating glucose concentrations relative to EL cows during infusion $(75.67 \pm 2.44$ vs. $62.32 \pm$ $2.44 \mathrm{mg} / \mathrm{dL}$, respectively) and after infusion (89.82 \pm 2.90 vs. $59.79 \pm 2.90 \mathrm{mg} / \mathrm{dL}$, respectively), with an abrupt increase in blood glucose concentrations $4 \mathrm{~h}$ after termination of infusion $(P=0.0002)$ relative to EL cows. No overall effect of EGTA infusion was observed during the infusion period $(P>0.05)$ on circulating glucose concentrations, but we detected a tendency for an infusion $\times$ stage interaction $(P=0.09)$ during the infusion period, with increased glucose concentrations in NL EGTA cows relative to NL Saline cows (77.69 \pm 2.72 vs. $73.65 \pm 2.90 \mathrm{mg} / \mathrm{dL}$ ) and decreased glucose concentrations in EL EGTA compared with EL Saline cows $(60.90 \pm 3.07$ vs. $63.74 \pm 2.56 \mathrm{mg} / \mathrm{dL}$, respectively).

Dry matter intake was unchanged in response to EGTA infusion $(P>0.05)$ but was affected by stage of lactation $(P=0.009)$, as EL cows had increased DMI relative to NL cows across the experimental period $(18.2 \pm 0.85$ vs. $12.8 \pm 0.85 \mathrm{~kg} / \mathrm{d}$, respectively; Figure $6 \mathrm{~B})$. Interestingly, an effect of day $(P=0.05)$ and stage $\times$ day was observed $(P=0.06)$, with DMI increasing across the experimental period, and more robustly in EL cows. Moreover, EL Saline cows had increased DMI relative to EL EGTA cows on d 3, with numerical increases in DMI relative to EL EGTA cows on d 2 and $\mathrm{d} 4(P=0.12$ and $P=0.16$, respectively $)$ of the experimental period. No differences in milk yield were observed because of infusion $(P>0.05$; EL EGTA $=$ 39.56 and EL Saline $=38.22 \mathrm{~kg} / \mathrm{d}$; Figure $6 \mathrm{C})$.

\section{DISCUSSION}

The onset of lactation requires a variety of physiological adaptations to meet the demands for milk synthesis as well as maternal metabolism. The dairy cow experiences a unique calcemic challenge during this time as a result of the abrupt shift in calcium demand. Calcemic demand during late gestation is often considered the nadir for the dairy cow, and early lactation is characterized by extreme calcium stress (Horst et al., 2005), which results in the early-lactation cow being placed in negative $\mathrm{Ca}$ balance. Thus, traditional mechanisms are often not sufficient alone, and classical Ca mechanisms may work in tandem with mammaryderived signals, such as serotonin and PTHLH. This results in a uniquely different Ca metabolism compared with an NL state. The data within recapitulate the distinct difference between EL and NL dairy cows in regards to Ca metabolism. Moreover, the present data also demonstrate how the mammary gland may play a

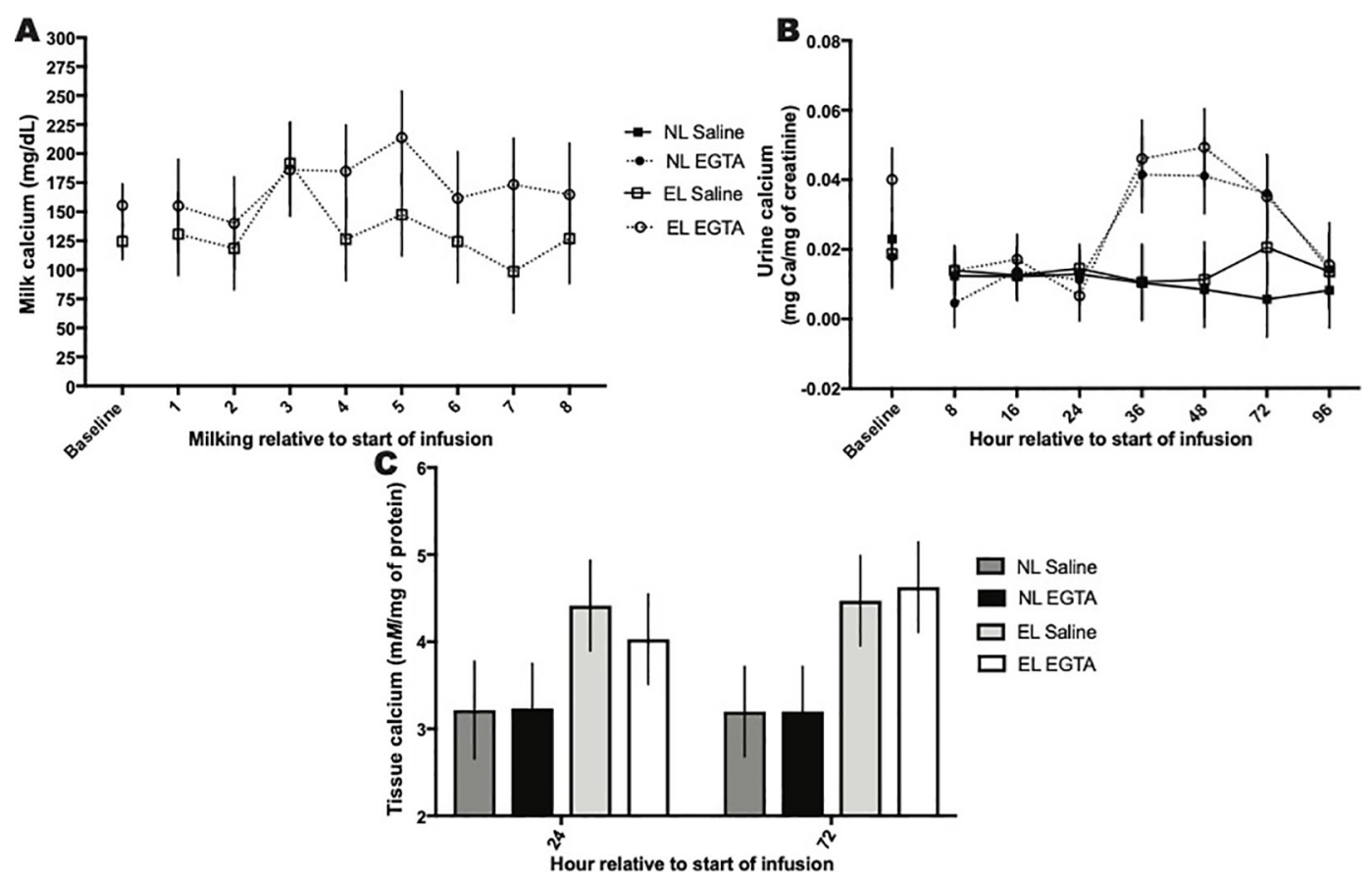

Figure 4. Milk calcium concentrations (A), urine calcium concentrations (B), and mammary tissue calcium content (C) in nonlactating, nonpregnant (NL) or early-lactation (EL) cows infused with 5\% ethylene glycol tetraacetic acid (NL EGTA and EL EGTA) or saline (NL Saline and EL Saline) for $24 \mathrm{~h}$. Urine calcium concentrations: infusion $(24 \mathrm{~h}: P=0.03$; post-termination: $P<0.0001)$ and stage (post-termination: $P$ $=0.03)$. Mammary tissue calcium content: stage $(P=0.01)$. Data presented as $\mathrm{LSM} \pm \mathrm{SEM}$. 

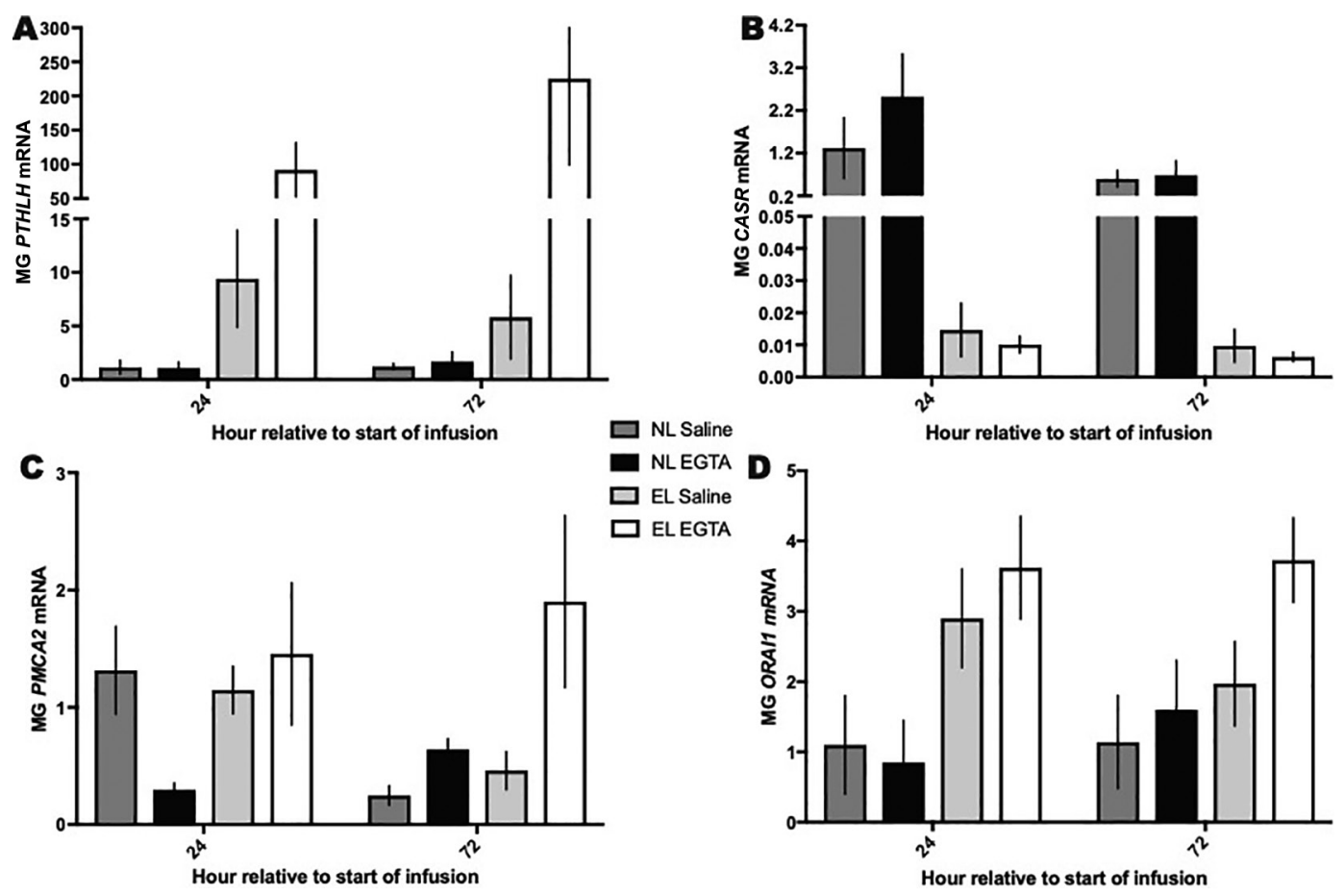

Figure 5. Mammary gland expression of (A) parathyroid hormone-related protein $(P T H L H)$, (B) calcium sensing receptor (CASR), (C) plasma membrane calcium ATPase 2 (PMCA2), and (D) calcium release activated channel 1 (ORAI1) in nonlactating, nonpregnant (NL) or early-lactation (EL) cows infused with $5 \%$ ethylene glycol tetraacetic acid (NL EGTA and EL EGTA) or saline (NL Saline and EL Saline) for 24 h. Mammary mRNA PTHLH expression: infusion $(P=0.0003)$, stage $(P<0.0001)$, infusion $\times$ stage $(P=0.002)$. Mammary mRNA $C A S R$ expression: stage $(P<0.0001)$. Mammary mRNA $P M C A 2$ expression: hour $(P=0.03)$ and infusion $\times$ hour $(P<0.0001)$. Mammary mRNA ORAI1 expression: stage $(P=0.005)$. Error bars represent SEM.

role in the adaptations to lactation that allow a more robust response to Ca perturbations in the EL dairy cow.

Interestingly, early-lactation cows required increased rates of EGTA infusion relative to NL cows to maintain $\mathrm{SCH}$ induction during the infusion period. During the first 4 to $5 \mathrm{~h}$ of SCH induction, both stages (EL and NL) had similar infusion rates and iCa concentrations, with differential responses being experienced after induction. Similar initial declines in blood Ca concentrations were observed in response to 5\% EGTA infusion in NL cows (Martinez et al., 2014) and in previous research with disodium ethylenediaminetetraacetate (EDTA) infused in NL and lactating cows (Ramberg et al., 1967). Earlier researchers referred to the initial timing in blood Ca decline in response to EDTA infusion as "phase 1" and believed it to represent the initial lag period before homeostatic adaptations take effect (Ramberg et al., 1967). Research in canines in response to EGTA infusion supported this phasic response and suggested that the readily available calcium pool is quickly depleted, and then Ca entry into circulation occurs at a much slower rate (Fox and Heath III, 1982). As EL EGTA cows progressed through the infusion period, significant increases in blood Ca concentrations occurred despite increases in infusion rates, suggesting that EL cows have more robust adaptations to lactation to support blood Ca maintenance compared with NL EGTA cows, who maintained more constant EGTA infusion rates and blood Ca concentrations.

Previous research suggested a triphasic pattern in blood Ca responses to Ca chelation, with an initial rapid decrease, followed by a plateau, and then a prompt decrease in blood $\mathrm{Ca}$ in lactating and NL cows and calves (Ramberg et al., 1967; Desmecht et al., 1995). Although the current study uses a different experimental model, with hourly EGTA adjustments, the present data also demonstrated a multiphasic response in infusion rate and blood Ca concentrations, but in opposing blood Ca directions. The EL EGTA cows exhibited a phasic response in EGTA infusion rates beginning at 4 to $8 \mathrm{~h}$ after start of infusion and analogous to when cows in both stages (NL and EL) reached SCH iCa maintenance concentrations. Correspondingly, a 3- to 7-h range after start of EDTA infusion is what Ramberg et al. (1967) termed "phase 1" (initial lag period before homeostatic adaptations) and during which cows experienced rapid $\mathrm{Ca}$ decline in response to chelation. 


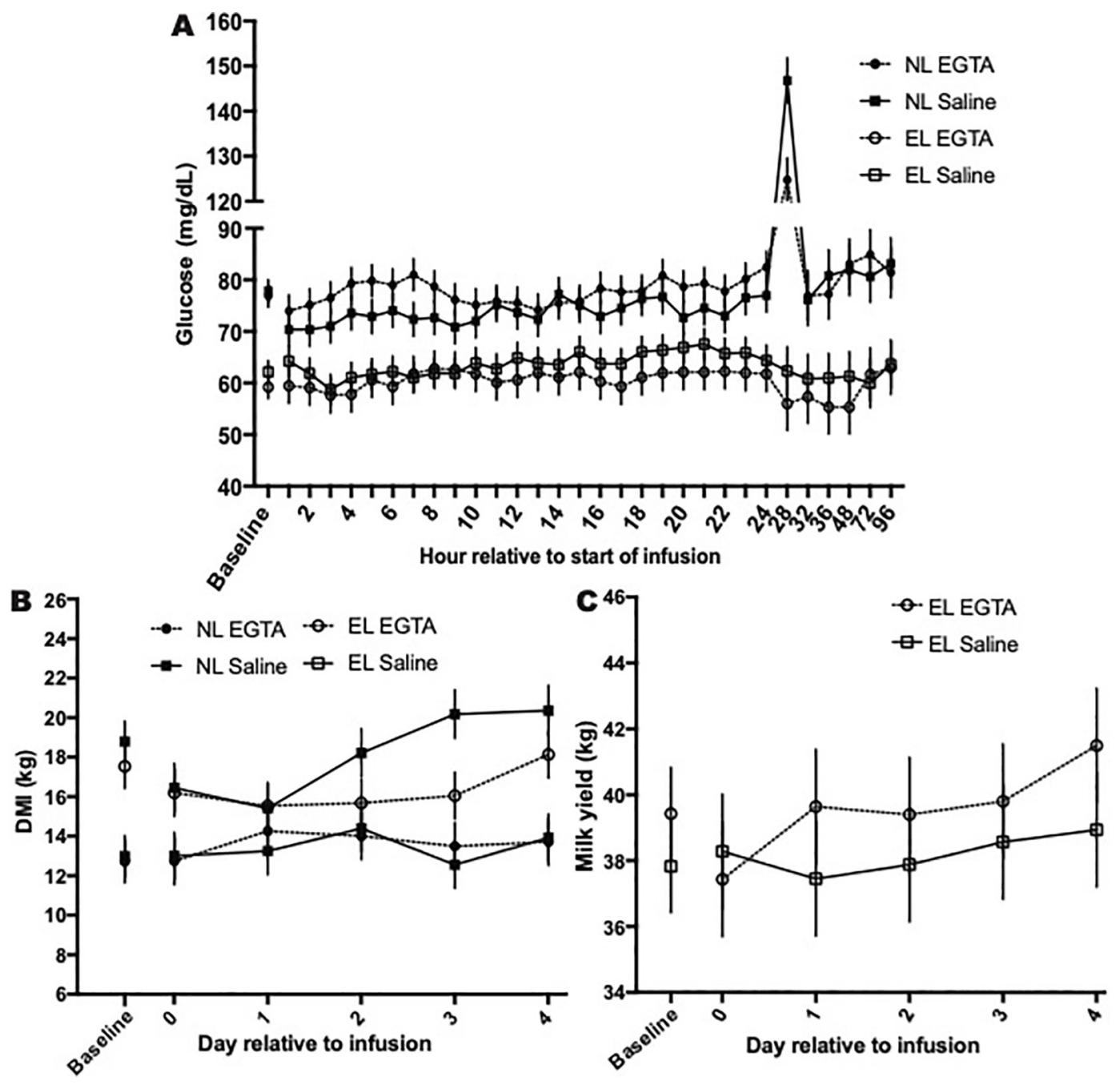

Figure 6. Glucose concentrations (A), DMI (B), and milk yield (C) in nonlactating, nonpregnant (NL) or early-lactation (EL) cows infused with 5\% ethylene glycol tetraacetic acid (NL EGTA and EL EGTA) or saline (NL Saline and EL Saline) for 24 h. Glucose concentrations: stage $(24$ h: $P=0.008$; post-termination: $P=0.0006)$, time $(24 \mathrm{~h}: P<0.0001$; post-termination: $P<0.0001)$, infusion $\times$ hour (post-termination: $P$ $=0.03)$, stage $\times$ hour $(24$ h: $P=0.02$; post-termination: $P<0.0001)$. Dry matter intake: stage $(P=0.009)$ and day $(P=0.05)$. Data presented as LSM \pm SEM.

In the current study, a bimodal-like response occurred, with peaks occurring at 14 to $15 \mathrm{~h}$ and in the last $22+\mathrm{h}$ of infusion. These infusion rate responses also overlap with previous work from Ramberg et al. (1967), in which adaptive calcemic responses were found to occur. Moreover, as EL EGTA cows experienced increased rates of EGTA infusion, simultaneous increases in blood Ca concentrations were observed. The phasic response in infusion rate and $\mathrm{iCa}$ concentrations in EL EGTA cows suggests that multiple systems may be integrating to regulate the adaptative response observed. Interestingly, NL EGTA cows maintained stable infusion rates and $\mathrm{iCa}$ concentrations once $\mathrm{SCH}$ was induced. However, differential responses between EL and NL EGTA-infused cows merit careful consideration when discussing mechanisms, as Ramberg et al. (1967) observed previously mentioned phasic responses in both lactating and nonlactating cows.

Early-lactation cows also exhibited adaptive responses to $\mathrm{Ca}$ chelation in the time following termination of infusion. Ionized and total Ca concentrations in EL EGTA cows were highest after termination of infusion, displaying a robust overcompensation to Ca chelation. The overcompensation in EL EGTA cows to Ca chelation resulted in an increase in $\mathrm{iCa}$ concentrations to approximately $1.3 \mathrm{mM}$ for $48 \mathrm{~h}$ after termination of infusion, and these cows did not return to blood $\mathrm{Ca}$ concentrations similar to other groups until $72 \mathrm{~h}$ after termination of infusion. The overcompensation and robust increase in blood Ca suggest that multiple sys- 
tems (bone, gut, rumen, kidney) may be supporting the prolonged blood Ca increase. Similar data trends were observed between $\mathrm{iCa}$ and tCa concentrations across the experimental period, with slight differences in iCa and tCa concentrations potentially observed as a result of acid-base status in relation to infusion and stage changes. Infusion of EGTA has been shown to successfully modify blood $\mathrm{pH}$, base excess, and $\mathrm{HCO}_{3}{ }^{-}(\mathrm{J} \varnothing \mathrm{r}-$ gensen et al., 1999), with acidosis alterations on blood $\mathrm{pH}$ causing Ca disassociation from albumin and thus introducing changes in the iCa:tCa ratio in the blood (Stogdale, 1981). Further, the present study observed acid-base differences because of stage, corresponding with previous literature demonstrating alterations and sensitivity changes in blood $\mathrm{pH}$ and $\mathrm{HCO}_{3}{ }^{-}$across lactation (Erdman et al., 1982; Delaquis and Block, 1995). Collectively, these data suggest that $\mathrm{Ca}$ chelation during early lactation activates a variety of homeostatic mechanisms to support blood $\mathrm{Ca}$, with early-lactation cows being differentially equipped to handle Ca perturbations via potential alterations in gut, rumen, kidney, bone, and mammary mechanisms.

Serotonin has been shown to be a critical regulator of Ca homeostasis during lactation (Laporta et al., 2014; Weaver et al., 2016), with substantial increases occurring in circulating serotonin during lactation (Bornstein et al., 2014; Moore et al., 2015). Recently, research has focused on serotonin's critical action as a hormone. The serotonin data presented herein demonstrate the dynamic action of serotonin during lactation. Circulating serotonin concentrations were increased in EL relative to NL cows, supporting previous data in rodents (Bornstein et al., 2014) and the serotonin profile characterized across lactation in dairy cows (Moore et al., 2015). Increasing circulating serotonin during lactation through administration of the serotonin precursor 5-HTP has been shown to elicit a transient hypocalcemia and modulate mammary Ca trafficking in mid- to late-lactation dairy cows (Laporta et al., 2015; Connelly et al., 2021b). However, understanding the opposing regulation of $\mathrm{Ca}$ perturbations on serotonin concentrations has not been explored. This experiment suggests that circulating and mammary serotonin concentrations are not altered in response to $\mathrm{Ca}$ perturbation (EGTA infusion), thus suggesting that the serotonin-Ca axis does not act in a feedback loop similar to that of the PTH-Ca axis, with serotonin concentrations not increasing or decreasing in response to blood Ca changes. This supports previous data in dry cows challenged with EGTA (Ca chelation) and lack of clear changes found in circulating serotonin concentrations (Amundson et al., 2018). However, clear changes were observed in circulating and mammary serotonin because of stage, as EL cows had higher circulating and mammary serotonin concentrations relative to NL cows. Work in rodents has suggested that $50 \%$ of circulating serotonin may be contributed through mammary-derived serotonin synthesis (Weaver et al., 2017), but to our knowledge this is the first work in the bovine demonstrating analogous increases in mammary and circulating serotonin concentrations in lactating relative to nonlactating cows. However, differences in serotonin concentrations between lactating and nonlactating dairy cows need to be more fully explored to characterize additional contributions of other serotonin-producing tissues that undergo hypertrophy and changes in serotonin metabolic activity during lactation (Takahashi et al., 2020; Connelly et al., 2021a).

Similar stage-specific changes in tissue Ca content occurred, with EL cows having increased mammary tissue Ca content. This is unsurprising, as the mammary gland experiences a large $\mathrm{Ca}$ load during lactation to support Ca excretion into milk (Lee et al., 2006), and supports previous work demonstrating increases in circulating serotonin, mammary serotonin content, and mammary Ca content collectively (Connelly et al., 2021b). Research has suggested that serotonin improves blood Ca by altering mammary Ca trafficking. Mammary expression of ORAI1 and PMCA2 were increased in EL relative to NL cows, but were not significantly different in relation to EGTA infusion. Mammary ORAI1 is a basolateral Ca transport channel essential for Ca entry into the mammary epithelial cell during lactation (Davis et al., 2015), with PMCA2 playing an equally important role in luminal mammary epithelial cell transport into milk (Reinhardt et al., 2004). Mammary Ca trafficking is regulated through a variety of receptors, channels, and pumps to ensure Ca transport into milk, with the 2 transporters mentioned previously being critical for $\mathrm{Ca}$ transport into milk during lactation and having been shown to be modulated by serotonin (Laporta et al., 2014; Connelly et al., 2021b). However, coinciding with circulating serotonin, mammary serotonin, and tissue serotonin content presented here, mammary Ca trafficking genes were primarily altered because of stage and not EGTA infusion. Unsurprisingly, a lack of significant changes in ORAI1 and PMCA2 expression in response to EGTA infusion coincided with milk Ca being not different between EL cows in response to EGTA infusion. The numerical elevation in milk Ca of EL EGTA-infused cows may be a result of the fluctuations in gene expression noted in ORAI1 and PMCA2 in EL EGTA-infused cows. However, the collective data suggest that Ca loss to the mammary gland may occur at a relatively fixed rate despite low blood Ca concentrations and then subsequent increased blood Ca concentrations in EL EGTA cows.

Mammary PTHLH has also been shown to be a potent bone mobilizer during lactation, stimulated by 
mammary-derived serotonin and critical for Ca liberation to support milk synthesis (Hernandez et al., 2012; Laporta et al., 2013a; VanHouten and Wysolmerski, 2013). Moreover, mammary PTHLH production has been shown to be regulated by CaSR, a G-protein coupled receptor on the mammary epithelial cell critical for coordinating mammary and systemic Ca metabolism (Ardeshirpour et al., 2006). Expression of mammary PTHLH was increased in EL cows relative to NL cows, and was robustly upregulated in EL EGTA relative to all other treatments across the experimental period. Mammary PTHLH and CASR were dynamic in EL cows, with robust increases in mammary PTHLH expression and significant downregulation in CASR observed. Activity of CaSR regulates PTHLH expression in the mammary gland, with CaSR sensing and responding to blood $\mathrm{Ca}$ concentrations. Inactivation of CaSR stimulates PTHLH production, whereas CaSR activation suppresses PTHLH in the mammary gland in an inverse fashion (Ardeshirpour et al., 2006; VanHouten and Wysolmerski, 2013). The aforementioned relationship is believed to be how the mammary gland may act as a calcium-sensing organ and is thus able to participate in systemic calcium homeostasis during lactation (Ardeshirpour et al., 2006), and is supported in the present gene expression data, as an inverse relationship is observed between PTHLH and CASR expression. Taken collectively, the substantial analogous increases in circulating serotonin, mammary serotonin, and mammary PTHLH expression in EL cows suggests that mammary-derived endocrine signals, such as serotonin and PTHLH, may be pertinent hormones in the EL cow's adaptation to lactation in terms of $\mathrm{Ca}$ homeostasis.

As mentioned, the EL dairy cow often experiences a negative Ca balance (Horst et al., 2005; Rodney et al., 2018) and relies extensively on skeletal reservoirs to maintain Ca homeostasis (Horst et al., 2005), and mammary-derived PTHLH is believed to be a large contributor to bone mobilization during lactation (VanHouten et al., 2003; VanHouten and Wysolmerski, 2013). Both urine DPD and serum PYD are common markers used as indication of bone resorption and thus insight into Ca release from bone. Unsurprisingly, EL cows, who also had upregulated mammary PTHLH expression and serotonin concentrations, additionally exhibited significantly elevated concentrations of both urine DPD and serum PYD (bone resorption indicators) relative to NL cows. This is not surprising, as the skeletal reserve is considered a major source of $\mathrm{Ca}$ supply during lactation, with dairy cows losing up to $13 \%$ of the skeletal $\mathrm{Ca}$ reservoir during the first 6 to 8 wk after parturition (Horst et al., 2005). However, no significant alterations in bone mobilization were de- tected based upon EGTA infusion in urine DPD or serum PYD concentrations, despite the EL EGTA cows' rigorous increases in PTHLH expression and $48 \mathrm{~h}$ of robustly increased blood $\mathrm{Ca}$ concentrations relative to all other groups. Previous research has suggested that bone resorption markers are not responsive to shortterm EDTA infusions (Liesegang et al., 2000), and thus 24-h Ca chelation may not have been able to sufficiently elicit clear concentration changes when already elevated as a result of lactation to detect differences between groups. Interestingly, infusion was significant after termination of $24 \mathrm{~h}$ of continuous infusion, as saline-infused cows had elevated urine DPD relative to EGTA-infused cows, suggesting that multiple calcium systems (bone, rumen, gut, kidney) may be facilitating the blood Ca responses rather than a single individual mechanism, which should be investigated more fully moving forward. Increased cow numbers and bone biopsies may provide clearer insight into bone's contribution and mechanism in EL EGTA cows' rigorous $\mathrm{Ca}$ responses to perturbation.

Non-chelated urine Ca was decreased in response to EGTA infusion, supporting previous research showing a rapid decline in non-chelated urine $\mathrm{Ca}$ in response to EDTA infusion (Schonewille et al., 1999). However, after termination of infusion, EGTA-infused cows rapidly increased urinary $\mathrm{Ca}$ excretion over the next $24+$ $\mathrm{h}$ relative to saline-infused cows. These increases in urinary $\mathrm{Ca}$ excretion following termination of infusion, specifically in EL EGTA cows, occurred simultaneously with rigorous increases in blood $\mathrm{Ca}$ concentrations. Thus, these data demonstrate that the EL dairy cow has a multitude of mechanisms to allow for robust adaptations to lactation to maintain $\mathrm{Ca}$ homeostasis regardless of Ca loss.

Glucose concentrations were unchanged in response to EGTA infusion but showed an interesting infusion $\times$ stage interaction, demonstrating differential glucose concentrations responses based upon stage. Earlylactation EGTA cows had lower circulating glucose concentrations compared with EL Saline cows, whereas NL EGTA cows had increased glucose concentrations relative to NL Saline cows. Increases in blood glucose often indicate a decrease in insulin production (Hayirli, 2006), with hypocalcemia being known to inhibit insulin release in the dairy cow (Littledike et al., 1968). However, previous work in cows supports this differential glucose response. Work in NL cows demonstrated hyperglycemia in EGTA-infused cows (Martinez et al., 2014), which was hypothesized to be driven by impaired pancreatic insulin secretion. However, lactating cows infused with EDTA experienced hypoglycemia (Ramberg et al., 1967), and work in sheep using an induced hypocalcemia model during lactation has 
demonstrated lowered endogenous production of glucose (Schlumbohm and Harmeyer, 2003). Although the differential response in this study poses interest and relevance when considering potential implications of low blood calcium concentrations on energy metabolism, this study did not aim to investigate energetic responses but, rather, to collect and report potential implications on hypocalcemia on glucose concentrations. Moreover, stage of lactation clearly altered circulating glucose, with early-lactation cows exhibiting lower circulating glucose concentrations relative to NL cows, as glucose demand outcompetes glucose supply in the EL cow because of glucose requirements for lactose synthesis (Drackley et al., 2001). A substantial increase in glucose concentrations occurred $4 \mathrm{~h}$ after termination of infusion and mammary gland biopsy in NL cows relative to EL cows. The general anesthetic xylazine is known to induce hyperglycemia and hypoinsulinemia (Hsu and Hummel, 1981). Potential explanations for differential responses may be from high glucose demand by the mammary gland and altered insulin status in EL cows (Baumgard et al., 2017) combined with intake differences, which would induce alterations in liver blood flow and metabolic clearance rates of drugs (Sangsritavong et al., 2002).

No differences were detected based upon EGTA infusion on milk yield and DMI across the experiment, despite previous work having shown that $\mathrm{Ca}$ chelation via EDTA or EGTA depresses DMI (Ramberg et al., 1967; Martinez et al., 2014). However, the present study encompassed differences in sampling and design. Our study used fewer cows (Martinez et al., 2014), evaluated DMI once a day (Martinez et al., 2014), and maintained a higher steady state of iCa concentrations during SCH (Ramberg et al., 1967; Martinez et al., 2014), and thus the aforementioned factors may affect lack of DMI response to EGTA infusion. Although DMI was not changed on infusion day, DMI remained lower during the ensuing days after infusion in EL EGTA cows relative to EL Saline cows. Interestingly, lower DMI in EL EGTA cows occurred in the ensuing days, while blood $\mathrm{Ca}$ was robustly increased relative to all other groups. Typically, Ca intake from the diet is a major contributor to blood Ca maintenance (Horst et al., 2005), suggesting that early-lactation cows may have multiple robust adaptations outside of intake alone to support the vigorous calcemic responses observed when compared with NL animals. One such adaptation may be ruminal $\mathrm{Ca}$ absorption, with recent research suggesting that the rumen can increase Ca absorptive capacity as a rapid-response mechanism to abrupt Ca perturbations (Hyde et al., 2019). Further, increases in intestinal $\mathrm{Ca}$ transport via both active and passive processes may also be part of the adaptive responses observed within this study (Horst et al., 2005). Unsurprisingly, stage of lactation was significant, as EL cows had increased intake, which is critical to support lactation and nutrient demand by the mammary gland (Goff et al., 2002). Milk yield was numerically lower on day of infusion in EL EGTA cows but rebounded and was numerically higher for the remainder of the experimental period, relative to EL Saline. However, no significant differences were detected between treatments. These results are unsurprising, considering that this experiment was not powered to analyze milk yield, but they pose interesting consideration when discussing blood calcium, DMI, and milk yield in the current study, as transient hypocalcemia in the immediate days postpartum has been associated with increased milk production when compared with normocalcemic cows (McArt and Neves, 2020), despite a lack of change in DMI (Seely et al., 2021).

\section{CONCLUSIONS}

Infusion of EGTA successfully induced SCH in both NL and EL dairy cows. However, the EL EGTA group required increased rates of EGTA infusion to maintain SCH while demonstrating rigorous adaptative responses to calcemic perturbation relative to the NL EGTA group. The NL EGTA group maintained more stable infusion rates and blood Ca concentrations relative to the EL EGTA group. Following termination of infusion, EL EGTA cows exhibited an overcompensation in blood Ca concentrations for approximately 48 h. Further, we observed clear differences in serotonin concentrations and mammary PTHLH expression as a result of stage, with circulating serotonin, mammary serotonin, and mammary PTHLH all significantly upregulated in EL cows. However, circulating serotonin and mammary serotonin content were not altered in response to EGTA infusion, but mammary PTHLH expression was robustly upregulated in EL EGTA cows. Thus, our data suggest that serotonin and PTHLH may be contributing players in the EL cow's calcemic adaptation to lactation and may play a role in the dairy cow's ability to successfully adapt to the demands of lactation. Collectively, the data herein clearly demonstrate that the EL cow is uniquely equipped to respond to Ca challenges and may utilize a multitude of systems to respond to lactational Ca demand.

\section{ACKNOWLEDGMENTS}

The authors thank all of the Dairy Cattle Center Staff at the University of Wisconsin-Madison (David Reimann, Luke Kastenson, and Caleb Hamm) and the fantastic assistance of the RARC Veterinary Staff (Mike 
Maroney, Kay Nelson, and Jane Reimann, Madison, WI). Financial support for the project was provided by United States Department of Agriculture-National Institute of Food and Agriculture (no. 2016-67015-34584; Washington, DC). The authors have not stated any conflicts of interest.

\section{REFERENCES}

Amundson, L. A., A. D. Rowson, P. M. Crump, A. P. Prichard, A. A. Cheng, C. E. Wimmler, M. Klister, S. R. Weaver, S. S. Bascom, D. E. Nuzback, K. P. Zanzalari, and L. L. Hernandez. 2018. Effect of induced hypocalcemia in nonlactating, nonpregnant Holstein cows fed negative DCAD with low, medium, or high concentrations of calcium. J. Anim. Sci. 96:5010-5023. https://doi.org/10.1093/jas/ sky371.

Ardeshirpour, L., P. Dann, M. Pollak, J. Wysolmerski, and J. VanHouten. 2006. The calcium-sensing receptor regulates PTHrP production and calcium transport in the lactating mammary gland. Bone 38:787-793. https://doi.org/10.1016/j.bone.2005.11.009.

Bauman, D. E., and W. Bruce Currie. 1980. Partitioning of nutrients during pregnancy and lactation: A review of mechanisms involving homeostasis and homeorhesis. J. Dairy Sci. 63:1514-1529. https:// doi.org/10.3168/jds.S0022-0302(80)83111-0.

Baumgard, L. H., R. J. Collier, and D. E. Bauman. 2017. A 100-Year Review: Regulation of nutrient partitioning to support lactation. J. Dairy Sci. 100:10353-10366. https://doi.org/10.3168/jds.2017 -13242 .

Berger, M., J. A. Gray, and B. L. Roth. 2009. The expanded biology of serotonin. Annu. Rev. Med. 60:355-366. https://doi.org/10.1146/ annurev.med.60.042307.110802.

Bornstein, S., S. A. Brown, P. T. Le, X. Wang, V. DeMambro, M. C. Horowitz, O. MacDougald, R. Baron, S. Lotinun, G. Karsenty, W. Wei, M. Ferron, C. S. Kovacs, D. Clemmons, Y. Wan, and C. J. Rosen. 2014. FGF-21 and skeletal remodeling during and after lactation in C57BL/6J mice. Endocrinology 155:3516-3526. https: //doi.org/10.1210/en.2014-1083.

Connelly, M. K., A. C. Cheng, and L. L. Hernandez. 2021a. Graduate Student Literature Review: Serotonin and calcium metabolism: A story unfolding. J. Dairy Sci. 104:13008-13019. https://doi.org/10 $.3168 /$ jds.2021-20610.

Connelly, M. K., S. R. Weaver, J. M. Kuehnl, H. P. Fricke, M. Klister, and L. L. Hernandez. 2021b. Elevated serotonin coordinates mammary metabolism in dairy cows. Physiol. Rep. 9:e14798. https:// doi.org/10.14814/phy2.14798.

Davis, F. M., A. Janoshazi, K. S. Janardhan, N. Steinckwich, D. M. D'Agostin, J. G. Petranka, P. N. Desai, S. J. Roberts-Thomson, G. S. Bird, D. K. Tucker, S. E. Fenton, S. Feske, G. R. Monteith, and J. W. Putney Jr.. 2015. Essential role of Orail store-operated calcium channels in lactation. Proc. Natl. Acad. Sci. USA 112:58275832. https://doi.org/10.1073/pnas.1502264112.

Delaquis, A. M., and E. Block. 1995. Dietary cation-anion difference, acid-base status, mineral metabolism, renal function, and milk production of lactating cows. J. Dairy Sci. 78:2259-2284. https:// doi.org/10.3168/jds.S0022-0302(95)76853-9.

Desmecht, D. J., A. S. Linden, J. M. Godeau, and P. M. Lekeux. 1995. Experimental production of hypocalcemia by EDTA infusion in calves: A critical appraisal assessed from the profile of blood chemicals and enzymes. Comp. Biochem. Physiol. A Physiol. 110:115-130. https://doi.org/10.1016/0300-9629(94)00156-N.

Drackley, J. K., T. R. Overton, and G. N. Douglas. 2001. Adaptations of glucose and long-chain fatty acid metabolism in liver of dairy cows during the periparturient period. J. Dairy Sci. 84(E-Suppl.):E100E112. https://doi.org/10.3168/jds.S0022-0302(01)70204-4.

Erdman, R. A., R. W. Hemken, and L. S. Bull. 1982. Dietary sodium bicarbonate and magnesium oxide for early postpartum lactating dairy cows: Effects on production, acid-base metabolism, and digestion. J. Dairy Sci. 65:712-731. https://doi.org/10.3168/jds .S0022-0302(82)82259-5.
Fox, J., and H. Heath III.. 1982. Parathyroid, renal, and skeletal responses to induced hypocalcemia in the dog. Am. J. Physiol. 242:E287-E291. https://doi.org/10.1152/ajpendo.1982.242.5 E287.

Goff, J. P. 2000. Pathophysiology of calcium and phosphorus disorders. Vet. Clin. North Am. Food Anim. Pract. 16:319-337. https:/ /doi.org/10.1016/S0749-0720(15)30108-0.

Goff, J. P., K. Kimura, and R. L. Horst. 2002. Effect of mastectomy on milk fever, energy, and vitamins $A, E$, and $\beta$-carotene status at parturition. J. Dairy Sci. 85:1427-1436. https://doi.org/10.3168/ jds.S0022-0302(02)74210-0.

Hayirli, A. 2006. The role of exogenous insulin in the complex of hepatic lipidosis and ketosis associated with insulin resistance phenomenon in postpartum dairy cattle. Vet. Res. Commun. 30:749 774. https://doi.org/10.1007/s11259-006-3320-6.

Hernandez, L. L., K. A. Gregerson, and N. D. Horseman. 2012. Mammary gland serotonin regulates parathyroid hormone-related protein and other bone-related signals. Am. J. Physiol. Endocrinol. Metab. 302:E1009-E1015. https://doi.org/10.1152/ajpendo.00666 2011.

Hernández-Castellano, L. E., L. L. Hernandez, H. Sauerwein, and R. M. Bruckmaier. 2017b. Endocrine and metabolic changes in transition dairy cows are affected by prepartum infusions of a serotonin precursor. J. Dairy Sci. 100:5050-5057. https://doi.org/10.3168/ jds.2016-12441.

Hernández-Castellano, L. E., L. L. Hernandez, S. Weaver, and R. M. Bruckmaier. 2017a. Increased serum serotonin improves parturient calcium homeostasis in dairy cows. J. Dairy Sci. 100:1580-1587. https://doi.org/10.3168/jds.2016-11638.

Horst, R. L., J. P. Goff, and T. A. Reinhardt. 2005. Adapting to the transition between gestation and lactation: Differences between rat, human and dairy cow. J. Mammary Gland Biol. Neoplasia 10:141-156. https://doi.org/10.1007/s10911-005-5397-x.

Hsu, W. H., and S. K. Hummel. 1981. Xylazine-induced hyperglycemia in cattle: A possible involvement of $\alpha_{2}$-adrenergic receptors regulating insulin release. Endocrinology 109:825-829. https://doi.org/ 10.1210/endo-109-3-825.

Hyde, M. L., M. R. Wilkens, and D. R. Fraser. 2019. In vivo measurement of strontium absorption from the rumen of dairy cows as an index of calcium absorption capacity. J. Dairy Sci. 102:5699-5705. https://doi.org/10.3168/jds.2018-16052.

Jørgensen, R. J., N. R. Nyengaard, R. C. Daniel, L. S. Mellau, and J. M. Enemark. 1999. Induced hypocalcaemia by Na2EDTA infusion. A review. Zentralbl. Veterinärmed. A 46:389-407. https://doi.org/ 10.1046/j.1439-0442.1999.00231.x.

Kovacs, C. S. 2016. Maternal mineral and bone metabolism during pregnancy, lactation, and post-weaning recovery. Physiol. Rev. 96:449-547. https://doi.org/10.1152/physrev.00027.2015.

Laporta, J., K. P. Keil, C. M. Vezina, and L. L. Hernandez. 2014. Peripheral serotonin regulates maternal calcium trafficking in mammary epithelial cells during lactation in mice. PLoS One 9:e110190. https://doi.org/10.1371/journal.pone.0110190.

Laporta, J., S. A. Moore, M. W. Peters, T. L. Peters, and L. L. Hernandez. 2013b. Short communication: Circulating serotonin (5HT) concentrations on day 1 of lactation as a potential predictor of transition-related disorders. J. Dairy Sci. 96:5146-5150. https:/ /doi.org/10.3168/jds.2013-6718.

Laporta, J., S. A. E. Moore, S. R. Weaver, C. M. Cronick, M. Olsen, A. P. Prichard, B. P. Schnell, T. D. Crenshaw, F. Penagaricano, R. M. Bruckmaier, and L. L. Hernandez. 2015. Increasing serotonin concentrations alter calcium and energy metabolism in dairy cows. J. Endocrinol. 226:43-55. https://doi.org/10.1530/JOE-14-0693.

Laporta, J., T. L. Peters, S. R. Weaver, K. E. Merriman, and L. L. Hernandez. 2013a. Feeding 5-hydroxy-L-tryptophan during the transition from pregnancy to lactation increases calcium mobilization from bone in rats. Domest. Anim. Endocrinol. 44:176-184. https://doi.org/10.1016/j.domaniend.2013.01.005.

Lee, W. J., G. R. Monteith, and S. J. Roberts-Thomson. 2006. Calcium transport and signaling in the mammary gland: Targets for breast cancer. Biochim. Biophys. Acta 1765:235-255. https://doi .org/10.1016/j.bbcan.2005.12.001. 
Liesegang, A., R. Eicher, M. L. Sassi, J. Risteli, J. L. Riond, and M. Wanner. 2000. The course of selected bone resorption marker concentrations in response to short-term hypocalcemia experimentally induced with disodium EDTA infusions in dairy cows. J. Vet. Med. A Physiol. Pathol. Clin. Med. 47:477-487. https://doi.org/ 10.1046/j.1439-0442.2000.00308.x.

Littledike, E. T., D. A. Witzel, and S. C. Whipp. 1968. Insulin: Evidence for inhibition of release in spontaneous hypocalcemia. Proc. Soc. Exp. Biol. Med. 129:135-139. https://doi.org/10.3181/ 00379727-129-33269.

Livak, K. J., and T. D. Schmittgen. 2001. Analysis of relative gene expression data using real-time quantitative PCR and the $2^{-\Delta \Delta \mathrm{CT}}$ method. Methods 25:402-408. https://doi.org/10.1006/meth.2001 .1262 .

Martinez, N., L. D. P. Sinedino, R. S. Bisinotto, E. S. Ribeiro, G. C. Gomes, F. S. Lima, L. F. Greco, C. A. Risco, K. N. Galvão, D. Taylor-Rodriguez, J. P. Driver, W. W. Thatcher, and J. E. P. Santos. 2014. Effect of induced subclinical hypocalcemia on physiological responses and neutrophil function in dairy cows. J. Dairy Sci. 97:874-887. https://doi.org/10.3168/jds.2013-7408.

McArt, J. A. A., and R. C. Neves. 2020. Association of transient, persistent, or delayed subclinical hypocalcemia with early lactation disease, removal, and milk yield in Holstein cows. J. Dairy Sci. 103:690-701. https://doi.org/10.3168/jds.2019-17191.

Merriman, K. E., N. Martinez, R. M. Rodney Harris, E. Block, J. E. P. Santos, and C. D. Nelson. 2019. Neutrophil $\beta$-defensin gene expression of postpartum dairy cows is altered by postpartum dietary cation-anion difference. J. Dairy Sci. 102:11636-11651. https://doi .org/10.3168/jds.2019-17216.

Moore, S. A., J. Laporta, T. D. Crenshaw, and L. L. Hernandez. 2015. Patterns of circulating serotonin and related metabolites in multiparous dairy cows in the peripartum period. J. Dairy Sci. 98:3754-3765. https://doi.org/10.3168/jds.2014-8841.

Ramberg, C. F. Jr., G. P. Mayer, D. S. Kronfeld, G. D. Aurbach, L. M. Sherwood, and J. T. Potts Jr.. 1967. Plasma calcium and parathyroid hormone responses to EDTA infusion in the cow. Am. J. Physiol. 213:878-882. https://doi.org/10.1152/ajplegacy.1967.213 .4 .878 .

Reinhardt, T. A., J. D. Lippolis, B. J. McCluskey, J. P. Goff, and R. L. Horst. 2011. Prevalence of subclinical hypocalcemia in dairy herds. Vet. J. 188:122-124. https://doi.org/10.1016/j.tvjl.2010.03.025.

Reinhardt, T. A., J. D. Lippolis, G. E. Shull, and R. L. Horst. 2004. Null mutation in the gene encoding plasma membrane $\mathrm{Ca}^{2}+$-ATPase isoform 2 impairs calcium transport into milk. J. Biol. Chem. 279:42369-42373. https://doi.org/10.1074/jbc.M407788200.

Rodney, R. M., N. Martinez, E. Block, L. L. Hernandez, P. Celi, C. D. Nelson, J. Santos, and I. J. Lean. 2018. Effects of prepartum dietary cation-anion difference and source of vitamin D in dairy cows: Vitamin D, mineral, and bone metabolism. J. Dairy Sci. 101:2519-2543. https://doi.org/10.3168/jds.2017-13737.

Sangsritavong, S., D. K. Combs, R. Sartori, L. E. Armentano, and M. C. Wiltbank. 2002. High feed intake increases liver blood flow and metabolism of progesterone and estradiol-17 $\beta$ in dairy cattle. J. Dairy Sci. 85:2831-2842. https://doi.org/10.3168/jds.S0022 $-0302(02) 74370-1$.

Schlumbohm, C., and J. Harmeyer. 2003. Hypocalcemia reduces endogenous glucose production in hyperketonemic sheep. J. Dairy Sci. 86:1953-1962. https://doi.org/10.3168/jds.S0022-0302(03)73783 -7 .

Schonewille, J. T., A. T. Van't Klooster, H. Wouterse, and A. C. Beynen. 1999. Hypocalcemia induced by intravenous administra- tion of disodium ethylenediaminotetraacetate and its effects on excretion of calcium in urine of cows fed a high chloride diet. J. Dairy Sci. 82:1317-1324. https://doi.org/10.3168/jds.S0022 -0302(99)75355-5.

Seely, C. R., B. M. Leno, A. L. Kerwin, T. R. Overton, and J. A. A. McArt. 2021. Association of subclinical hypocalcemia dynamics with dry matter intake, milk yield, and blood minerals during the periparturient period. J. Dairy Sci. 104:4692-4702. https://doi .org/10.3168/jds.2020-19344.

Slater, C. J., E. L. Endres, S. R. Weaver, A. A. Cheng, M. R. Lauber, S. F. Endres, E. Olstad, A. DeBruin, P. M. Crump, E. Block, and L. L. Hernandez. 2018. Interaction of 5-hydroxy-L-tryptophan and negative dietary cation-anion difference on calcium homeostasis in multiparous peripartum dairy cows. J. Dairy Sci. 101:5486-5501. https://doi.org/10.3168/jds.2017-13938.

Stogdale, L. 1981. Correlation of changes in blood chemistry with pathological changes in the animal's body: II Electrolytes, kidney function tests, serum enzymes, and liver function tests. J. S. Afr. Vet. Assoc. 52:155-164.

Takahashi, M., T. Miyatsuka, L. Suzuki, S. Osonoi, M. Himuro, M. Miura, T. Katahira, Y. Wakabayashi, A. Fukunaka, Y. Nishida, Y. Fujitani, S. Takeda, H. Mizukami, A. Itakura, and H. Watada. 2020. Biphasic changes in $\beta$-cell mass around parturition are accompanied by increased serotonin production. Sci. Rep. 10:4962 https://doi.org/10.1038/s41598-020-61850-1.

VanHouten, J. N., P. Dann, A. F. Stewart, C. J. Watson, M. Pollak, A. C. Karaplis, and J. J. Wysolmerski. 2003. Mammary-specific deletion of parathyroid hormone-related protein preserves bone mass during lactation. J. Clin. Invest. 112:1429-1436. https://doi .org/10.1172/JCI200319504.

VanHouten, J. N., and J. J. Wysolmerski. 2013. The calcium-sensing receptor in the breast. Best Pract. Res. Clin. Endocrinol. Metab. 27:403-414. https://doi.org/10.1016/j.beem.2013.02.011.

Venjakob, P. L., R. Staufenbiel, W. Heuwieser, and S. Borchardt. 2021. Association between serum calcium dynamics around parturition and common postpartum diseases in dairy cows. J. Dairy Sci 104:2243-2253. https://doi.org/10.3168/jds.2019-17821.

Weaver, S. R., and L. L. Hernandez. 2018. Could use of selective serotonin reuptake inhibitors during lactation cause persistent effects on maternal bone? J. Mammary Gland Biol. Neoplasia 23:5-25. https://doi.org/10.1007/s10911-018-9390-6.

Weaver, S. R., N. J. Jury, K. A. Gregerson, N. D. Horseman, and L. L. Hernandez. 2017. Characterization of mammary-specific disruptions for Tph1 and Lrp5 during murine lactation. Sci. Rep. 7:15155. https://doi.org/10.1038/s41598-017-15508-0.

Weaver, S. R., A. P. Prichard, E. L. Endres, S. A. Newhouse, T. L. Peters, P. M. Crump, M. S. Akins, T. D. Crenshaw, R. M. Bruckmaier, and L. L. Hernandez. 2016. Elevation of circulating serotonin improves calcium dynamics in the peripartum dairy cow. J. Endocrinol. 230:105-123. https://doi.org/10.1530/JOE-16-0038.

\section{ORCIDS}

M. K. Connelly ๑ https://orcid.org/0000-0001-8209-9523 S. R. Henschel $\odot$ https://orcid.org/0000-0001-5553-0971 A. A. Cheng @ https://orcid.org/0000-0001-6995-6690

L. L. Hernandez @ https://orcid.org/0000-0001-7591-5203 